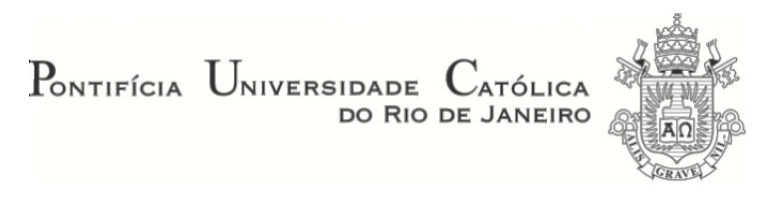

Fábio Brener Roitman

\title{
Discriminação de Preços de Passagens \\ Aéreas no Mercado Brasileiro
}

\section{Dissertação de Mestrado}

Dissertação apresentada ao Programa de PósGraduação em Economia da PUC-Rio como requisito parcial para obtenção do título de Mestre em Economia.

Orientador: Prof. Leonardo Bandeira Rezende 


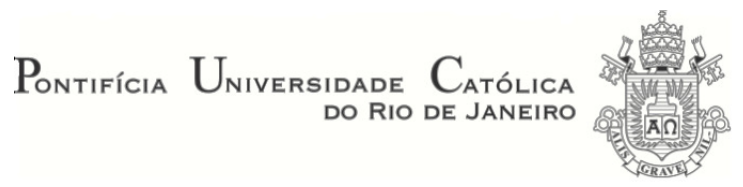

Fábio Brener Roitman

\title{
Discriminação de Preços de Passagens Aéreas no Mercado Brasileiro
}

\begin{abstract}
Dissertação apresentada ao Programa de PósGraduação em Economia da PUC-Rio como requisito parcial para obtenção do título de Mestre em Economia. Aprovada pela Comissão Examinadora abaixo assinada.
\end{abstract}

Prof. Leonardo Bandeira Rezende Orientador Departamento de Economia - PUC-Rio

Prof. João Manoel Pinho de Mello Departamento de Economia - PUC-Rio

Prof. Ronaldo Serôa da Motta IBMEC/RJ

Prof $^{\text {a }}$. Mônica Herz Coordenadora Setorial do Centro de Ciências Sociais - PUC-Rio 
Todos os direitos reservados. É proibida a reprodução total ou parcial do trabalho sem a autorização da universidade, do autor e do orientador.

Fábio Brener Roitman

Graduou-se em Economia pela Universidade Federal do Rio de Janeiro (UFRJ) em 2008.

Ficha Catalográfica

Roitman, Fábio Brener

Discriminação de preços de passagens aéreas no mercado brasileiro / Fábio Brener Roitman; orientador: Leonardo Bandeira Rezende. - Rio de Janeiro: PUC-Rio, Departamento de Economia, 2013.

46 f. ; $29,7 \mathrm{~cm}$

Dissertação (mestrado)-Pontifícia Universidade Católica do Rio de Janeiro, Departamento de Economia.

Inclui referências bibliográficas.

1. Economia - Teses. 2. Discriminação de preços. 3. Dispersão de preços. 4. Disposição a pagar. 5. Bem-estar. 6. Transporte aéreo. I. Rezende, Leonardo Bandeira. II. Pontifícia Universidade Católica do Rio de Janeiro. Departamento de Economia. III. Título.

CDD: 330 


\section{Agradecimentos}

A Leonardo Rezende, cuja orientação contribuiu enormemente para este trabalho e para minha formação. Agradeço pelo muito que aprendi de teoria econômica e de pesquisa, e também pela serenidade, otimismo e apoio transmitidos ao longo do processo de elaboração desta dissertação.

A João Manoel Pinho de Mello e Ronaldo Serôa da Motta, que ajudaram a aprimorar este trabalho com seus comentários e sugestões.

Aos professores do Departamento de Economia da PUC-Rio pelos excelentes cursos ministrados e à equipe administrativa pela disponibilidade e ajuda.

Ao Conselho Nacional de Desenvolvimento Científico e Tecnológico (CNPq) e à Coordenação de Aperfeiçoamento de Pessoal de Nível Superior (Capes) por terem concedido auxílio financeiro durante o Mestrado.

À Agência Nacional de Aviação Civil (em particular, à Gerência de Análise Estatística e Acompanhamento de Mercado) por ter disponibilizado parte dos dados utilizados neste trabalho.

A William Saab, Guilherme Maia e Eriksom Lima pelo apoio e colaboração.

Aos meus colegas e amigos do Mestrado, com quem tive (e espero continuar a ter) a oportunidade de conviver e aprender, dentro e fora da sala de aula.

À minha avó e ao meu avô (in memoriam), com quem desde cedo aprendi muito.

A meus pais, presentes em todos os momentos com compreensão e carinho, agradeço por tudo que me ensinaram e fizeram por mim. 


\section{Resumo}

Roitman, Fábio Brener; Rezende, Leonardo Bandeira. Discriminação de Preços de Passagens Aéreas no Mercado Brasileiro. Rio de Janeiro, 2013. 46p. Dissertação de Mestrado - Departamento de Economia, Pontifícia Universidade Católica do Rio de Janeiro.

Nesta dissertação, estuda-se a discriminação de preços no transporte aéreo brasileiro. A base de dados, construída a partir das respostas dos passageiros na Pesquisa $\mathrm{O} / \mathrm{D}$, contém informações a que as companhias aéreas não têm acesso. Passageiros com maior renda e que viajam a trabalho pagam preços maiores, e o uso de vários controles nas regressões permite concluir que isso é explicado, em parte, por discriminação de preços. Desenvolve-se um modelo empírico de discriminação de preços, em que uma firma utiliza os atributos das passagens para prever a disposição a pagar dos consumidores e, assim, estabelecer os preços. Empregando as estimativas dos parâmetros do modelo, consideram-se cenários contrafactuais em que há restrições sobre a discriminação de preços. Em média, restringir a discriminação de preços geraria uma redução do excedente do consumidor da ordem de $10 \%$.

\section{Palavras-chave}

Discriminação de preços; dispersão de preços; disposição a pagar; bemestar; transporte aéreo. 


\section{Abstract}

Roitman, Fábio Brener; Rezende, Leonardo Bandeira (Advisor). Price Discrimination in the Brazilian Airline Market. Rio de Janeiro, 2013. 46p. MSc Dissertation - Departamento de Economia, Pontifícia Universidade Católica do Rio de Janeiro.

This dissertation studies price discrimination in the Brazilian airline market. The data used are from the O/D Survey, which involved interviews with passengers. This enables us to have in our data set information that airlines do not have. Business travelers and those with higher incomes pay higher prices. By including several controls in the regressions, we obtain evidence that this is due to price discrimination, at least to some extent. We develop an empirical model of price discrimination, in which a firm uses ticket attributes to predict consumers' willingness to pay and thus sets its prices. The model's estimated parameters are used to construct counterfactual scenarios where price discrimination is constrained. On average, restricting price discrimination would reduce consumer surplus by approximately $10 \%$.

\section{Keywords}

Price discrimination; price dispersion; willingness to pay; welfare; air transportation. 


\section{Sumário}

1 Introdução

2 Dados

14

2.1. O setor de transporte aéreo brasileiro nos anos 2000

2.2. Fontes de dados 15

2.3. Estatísticas descritivas 16

3 Dispersão e discriminação de preços 18

3.1. Dispersão de preços: possíveis explicações 18

3.2. Regressões em forma reduzida 19

4 Um modelo empírico de discriminação de preços 22

4.1. Modelo 22

4.2. Resolução 24

4.3. Estimação 25

4.4. Especificação econométrica 26

4.5. Estimativas 27

5 Implicações sobre o bem-estar 30

5.1. Mensuração 30

5.2. Exercícios contrafactuais 31

6 Conclusão 35

7 Referências bibliográficas $\quad 36$

8 Apêndice 38

8.1. Dados 38

8.2. Desenvolvimentos algébricos 41

8.3. Figuras e tabelas 42 


\section{Lista de tabelas}

$\begin{array}{ll}\text { Tabela } 1 \text { - Estatísticas descritivas } & 16\end{array}$

Tabela 2 - Regressões em forma reduzida 21

Tabela 3 - Estimativas dos parâmetros do modelo 28

Tabela 4 - Preços (em R $\$$ ) no modelo e nos contrafactuais 33

Tabela 5 - Variação percentual das medidas de bem-estar entre cada contrafactual e o modelo 34

Tabela 6 - Preços (em R $\$$ ) no modelo e nos contrafactuais, com base nos parâmetros estimados na especificação (1)

Tabela 7 - Preços (em $\mathrm{R} \$$ ) no modelo e nos contrafactuais, com base nos parâmetros estimados na especificação (2)

Tabela 8 - Variação percentual das medidas de bem-estar entre cada contrafactual e o modelo, com base nos

parâmetros estimados na especificação (1)

Tabela 9 - Variação percentual das medidas de bem-estar entre cada contrafactual e o modelo, com base nos

parâmetros estimados na especificação (2) 


\section{Lista de figuras}

Figura 1 - Histograma do preço da Gol na rota $\begin{array}{ll}\text { Congonhas-Santos Dumont } & 17\end{array}$

Figura 2 - Relação entre $\operatorname{Pr}\left(\mathrm{WTP} \geq \mathrm{p} \mid \mathrm{z}^{\mathrm{R}}\right)$ e $\mathrm{p}$ 


\section{Lista de Abreviaturas}

Anac Agência Nacional de Aviação Civil

BSB Aeroporto Pres. Juscelino Kubitschek (Brasília)

CGB Aeroporto Marechal Rondon (Cuiabá)

CGH Aeroporto de Congonhas (São Paulo)

CGR Aeroporto de Campo Grande (Campo Grande)

CNF Aeroporto Tancredo Neves (Belo Horizonte)

CWB Aeroporto Afonso Pena (Curitiba)

DAC Departamento de Aviação Civil

Fipe $\quad$ Fundação Instituto de Pesquisas Econômicas

FLN Aeroporto Hercílio Luz (Florianópolis)

FOR Aeroporto Pinto Martins (Fortaleza)

GIG Aeroporto do Galeão (Rio de Janeiro)

GRU Aeroporto de Guarulhos (São Paulo)

Hotran Horário de Transporte

IATA International Air Transport Association

IPCA Índice de Preços ao Consumidor Amplo

ITA Instituto Tecnológico de Aeronáutica

MAO Aeroporto Eduardo Gomes (Manaus)

NAT Aeroporto Augusto Severo (Natal)

POA Aeroporto Salgado Filho (Porto Alegre)

REC Aeroporto dos Guararapes (Recife)

SDU Aeroporto Santos Dumont (Rio de Janeiro)

SSA Aeroporto Dep. Luís Eduardo Magalhães (Salvador)

VCP Aeroporto de Viracopos (Campinas) 


\section{1 \\ Introdução}

A companhia aérea responsável pelo voo 3909 de 24/08/2012 oferecia, em 21/07/2012, passagens a 5 diferentes preços para esse voo, sendo o menor R 129 e o maior R $\$ 989^{1}$. Tamanha dispersão de preços não é uma peculiaridade desse voo ou do mercado brasileiro. A dispersão de preços de passagens aéreas é um objeto de estudo na literatura desde Borenstein \& Rose (1994).

Nesta dissertação, utilizam-se dados do mercado brasileiro para analisar uma das explicações para a dispersão de preços de passagens aéreas: a discriminação de preços. Um modelo empírico de discriminação de preços é desenvolvido. Nele, uma firma utiliza os atributos das passagens para prever a disposição a pagar dos consumidores e, assim, estabelecer os preços. Empregando as estimativas dos parâmetros do modelo, são realizados exercícios contrafactuais, de forma a medir o impacto sobre o bem-estar da imposição de restrições sobre a discriminação de preços.

Os dados são provenientes da Pesquisa O/D, uma pesquisa com passageiros realizada nos aeroportos brasileiros. Além de informações sobre a passagem, estão disponíveis na base de dados informações a que as companhias aéreas não têm acesso, como a renda do passageiro e se a viagem é a trabalho.

A análise da discriminação de preços é desenvolvida em três partes. Primeiro, são apresentadas regressões em forma reduzida. A regressão com mais controles, incluindo efeitos fixos de voo, indica que o preço é $21.4 \%$ maior para passageiros que viajam a trabalho. Argumenta-se que isso é uma evidência de discriminação de preços.

A parte central da análise é o modelo empírico de discriminação de preços. Considera-se uma firma que vende passagens para diferentes rotas e voos, as quais podem ser adquiridas com maior ou menor antecedência. Para estabelecer o preço

\footnotetext{
${ }^{1}$ Preços coletados no portal da companhia aérea na Internet. As passagens diferem em alguns aspectos, como taxas de alteração e cancelamento e pontuação no programa de milhagem. O voo 3909 liga o aeroporto Santos Dumont, no Rio de Janeiro, ao aeroporto de Congonhas, em São Paulo.
} 
da passagem para cada combinação de rota, voo e antecedência, a firma prevê a disposição a pagar dos consumidores com base nos atributos da passagem. A comparação entre o preço no modelo e o preço efetivamente cobrado permite estimar como os atributos das passagens afetam a disposição a pagar dos consumidores. Os coeficientes estimados são empregados para obter a relação entre a disposição a pagar e características dos consumidores não observadas pela firma.

Na terceira parte da análise, utilizam-se as estimativas dos parâmetros do modelo para avaliar o bem-estar. São considerados cenários contrafactuais em que a firma tem menor capacidade de discriminar preços - por exemplo, porque deve cobrar um preço único para todas as passagens em uma rota. Nos cenários contrafactuais, a firma deixaria de oferecer passagens a preços reduzidos na maior parte das rotas, e o excedente do consumidor teria, em média, uma redução da ordem de $10 \%$. Assim, restrições sobre a discriminação de preços reduziriam não apenas o lucro, mas também o excedente do consumidor e o bem-estar social.

A dissertação insere-se na literatura empírica de dispersão de preços de passagens aéreas. Utilizando dados do mercado norte-americano, Borenstein \& Rose (1994) documentam significativa dispersão de preços de passagens aéreas de uma empresa em uma rota e encontram evidências de que a dispersão é maior em rotas em que há mais competição. Esse resultado coincide com o obtido por Stavins (2001) e difere das conclusões de Gerardi \& Shapiro (2009). Explicações para a dispersão de preços que não passam pela discriminação de preços são examinadas em Escobari \& Gan (2007) e Puller et al. (2009).

Os estudos com os quais a dissertação guarda maior relação são aqueles que tratam especificamente da discriminação de preços de passagens aéreas. Oliveira et al. (2006) e Rochlin (2011) fazem análises empíricas do tema aplicadas ao mercado brasileiro. Puller \& Taylor (2012) mostram que empresas norteamericanas usam o dia da semana de aquisição da passagem para discriminar preços. Lazarev (2012) emprega uma abordagem estrutural e desenvolve um modelo em que a companhia aérea estabelece preços de acordo com a antecedência da compra. O modelo é estimado para rotas domésticas norteamericanas em que há monopólio. Exercícios contrafactuais indicam que, sem discriminação intertemporal de preços, o bem-estar social seria maior. 
Nossa análise tem objetivos semelhantes aos de Lazarev (2012), mas difere na forma de modelar a discriminação de preços. Não modelamos a escolha do consumidor entre diferentes passagens. Por outro lado, incorporamos no modelo variáveis não observadas pela companhia aérea, o que é possível porque os dados são provenientes dos consumidores.

A dissertação está dividida em 6 seções, incluindo esta introdução. $\mathrm{Na}$ seção 2, apresentam-se os dados empregados. Possíveis explicações para a dispersão de preços de passagens aéreas, com ênfase na discriminação de preços, são examinadas na seção 3. O modelo empírico de discriminação de preços e sua estimação estão na seção 4. As implicações do modelo sobre o bem-estar são analisadas na seção 5, em que são apresentados os exercícios contrafactuais. Seguem, na seção 6, as conclusões. 


\section{2 \\ Dados}

\section{1.}

O setor de transporte aéreo brasileiro nos anos 2000

Consolidou-se nos anos 2000 o processo de liberalização do setor de transporte aéreo brasileiro, iniciado na década de 1990. Diversas restrições sobre o preço das passagens foram removidas. Em 2001, passou a vigorar o regime de liberdade tarifária no transporte aéreo doméstico². A liberalização envolveu, ainda, o fim de monopólios definidos pelo Estado e maior permissividade à entrada de novas companhias aéreas.

Entre 2000 e 2009, foram intensas a saída e a entrada de empresas. Das 5 empresas com maior participação no mercado doméstico em 2000, apenas uma - a Tam - continuava a operar em 2009. Por outro lado, entre as 5 companhias com maior participação no mercado doméstico em 2009, 4 entraram no mercado depois de 2000 (DAC, 2001; Anac, 2010). Uma das entrantes, a Gol, disputava a liderança do mercado com a Tam. Essas empresas detinham, respectivamente, $42 \%$ e $45 \%^{3}$ do mercado doméstico em 2009 (Anac, 2010).

Houve, nos anos 2000, tendências de expansão do mercado doméstico e de redução do preço das passagens. $\mathrm{O}$ indicador de passageiro quilômetro pago transportado (somatório das distâncias percorridas por passageiro pago) teve um crescimento de 105\% entre 2002 e 2009 (Anac, 2010). Nesse período, o yield tarifa (preço médio pago por passageiro por quilômetro voado), atualizado pelo IPCA, registrou queda de 33\% (Anac, 2011).

${ }^{2} \mathrm{O}$ regime de liberdade tarifária foi instituído pela Portaria $\mathrm{n}^{\circ} 248$ do Ministério da Fazenda, de 10 de agosto de 2001.

${ }^{3}$ Participações de mercado calculadas com base no indicador de passageiro quilômetro pago transportado. 


\section{2. Fontes de dados}

Os dados utilizados na dissertação são referentes ao ano de 2009, meses de julho e agosto. Nesse período, foi realizada a Pesquisa O/D, que envolveu entrevistas com passageiros nas salas de embarque de 32 aeroportos brasileiros. Os resultados agregados da Pesquisa $\mathrm{O} / \mathrm{D}^{4}$ estão publicados em McKinsey \& Company (2010). Único estudo que conhecemos que utiliza dados da Pesquisa O/D, McKinsey \& Company (2010) não analisa o preço das passagens aéreas.

Além de informarem o número do voo, preço da passagem e antecedência da compra, os entrevistados na Pesquisa O/D reportaram sua renda e o responsável pelo pagamento da passagem. Essas são informações não conhecidas pela companhia aérea e úteis à análise de discriminação de preços. Os estudos sobre discriminação de preços de passagens aéreas de que temos conhecimento utilizam dados oriundos, em última instância, das empresas. Dados provenientes dos consumidores, como no caso da Pesquisa O/D, estão mais sujeitos a erros de medida, mas têm a vantagem de conterem informações que as companhias aéreas não possuem.

A Pesquisa O/D foi conduzida pela Fundação Instituto de Pesquisas Econômicas (Fipe), que utilizou amostragem por cotas. A partir dos dados de tráfego de passageiros, foram definidas cotas para cada par de aeroportos de origem e destino. Para que a amostra selecionada fosse representativa do universo de passageiros que se deslocam entre dois aeroportos, ocorreram entrevistas em todos os dias da semana e horários em que havia voos entre os dois aeroportos.

Uma observação na base de dados é um passageiro entrevistado na Pesquisa O/D. Foram considerados passageiros em itinerários domésticos que voaram diretamente da origem para o destino, isto é, não fizeram escala nem conexão. Restringiu-se a base de dados às 117 rotas com mais observações. Rota, nesta dissertação, é definida como o deslocamento entre dois aeroportos, independente do sentido em que se dá o deslocamento.

Informações fornecidas pela Anac e pelo Instituto Tecnológico de Aeronáutica (ITA) complementam a base de dados. A Anac forneceu dados

\footnotetext{
${ }^{4}$ Os microdados da Pesquisa O/D estão disponíveis em: <www.bndes.gov.br/SiteBNDES/export/sites/default/bndes_pt/Galerias/Arquivos/empresa/pesquis a/chamada3/20100125-BD_completo.zip>
} 
relativos à ocupação dos voos, à distância percorrida e ao consumo de combustível. O ITA é a fonte dos dados de utilização da capacidade dos aeroportos.

\section{3. \\ Estatísticas descritivas}

A base de dados é formada por 16163 passageiros (observações), que se distribuem por 9 companhias aéreas e por 117 rotas. O número de observações é maior em rotas com maior tráfego de passageiros. Assim, há 1057 observações na rota Congonhas-Santos Dumont e 8 na rota Congonhas-Porto Seguro. Como os passageiros na base de dados estão dispersos em muitos voos, há poucas observações no mesmo voo. Definindo-se um voo por seu número, aeroportos de origem e destino e sua data, são 6841 voos. Em 49\% deles, há apenas uma observação.

Estatísticas descritivas de algumas variáveis são apresentadas na Tabela 1. Em média, os passageiros na base de dados adquirem a passagem com, aproximadamente, uma semana de antecedência e pagam $\mathrm{R} \$ 327$. A média da renda mensal familiar per capita é $\mathrm{R} \$ 4240$. Quase metade dos passageiros viaja a trabalho, em que se considera que a viagem é a trabalho se a passagem é paga pelo órgão de trabalho do passageiro.

Tabela 1 - Estatísticas descritivas

\begin{tabular}{llcc}
\hline Variável & Definição & Média & $\begin{array}{c}\text { Desvio } \\
\text { padrão }\end{array}$ \\
\hline preço & Valor pago pela passagem, em R\$ & 327 & 185 \\
antecedência & № de semanas completas entre a compra e o voo & 1.25 & 1.47 \\
renda & Renda mensal familiar per capita, em R $\$$ & 4240 & 5249 \\
trabalho & Dummy que indica que a viagem é a trabalho & 0.48 & 0.50 \\
\hline Notas: (1) 16163 observações. (2) Definições detalhadas das variáveis estão no Apêndice. &
\end{tabular}

Busca-se medir, na base de dados, a dispersão de preços de passagens de uma companhia aérea em uma rota. A título de ilustração, mostra-se o histograma do preço de passagem da empresa Gol na rota Congonhas-Santos Dumont ${ }^{5}$ (Figura 1). A distribuição do preço é bimodal e tem uma larga amplitude, sugerindo uma dispersão significativa.

\footnotetext{
${ }^{5}$ Congonhas-Santos Dumont pela Gol é a rota-companhia aérea em que há o maior número de observações na base de dados.
} 
Figura 1 - Histograma do preço da Gol na rota Congonhas-Santos Dumont

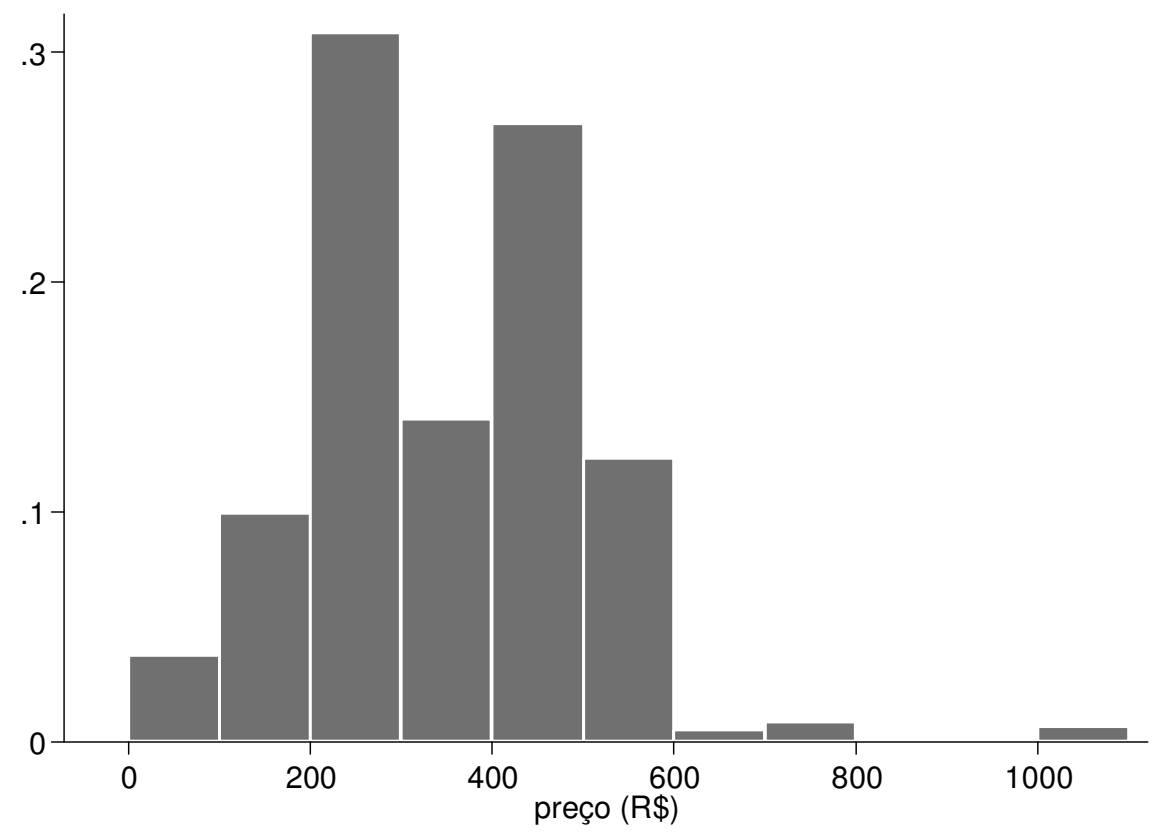

Notas: (1) No eixo vertical, apresenta-se a fração de observações em cada faixa. (2) Total de 584 observações.

Na literatura, é usual utilizar o coeficiente de Gini para medir a dispersão de preços de passagens de uma companhia aérea em uma rota. $\mathrm{O}$ dobro do coeficiente de Gini é igual à média da diferença, em valor absoluto, entre os preços de duas passagens, expressa como proporção do preço médio.

Calculou-se o coeficiente de Gini para cada rota-companhia aérea em que há mais de 100 observações na base de dados ${ }^{6}$. A mediana é 0.24 , o que indica uma substancial dispersão: na rota-companhia aérea mediana, a média da diferença de preço entre duas passagens é igual a $48 \%$ do preço médio. O coeficiente de Gini de 0.24 é próximo dos valores encontrados na literatura para o mercado norteamericano. Borenstein \& Rose (1994) e Gerardi \& Shapiro (2009) obtêm coeficientes de Gini iguais a 0.18 e 0.22 , respectivamente.

\footnotetext{
${ }^{6}$ Atendem a esse requisito 44 combinações de rota e companhia aérea.
} 


\section{3 \\ Dispersão e discriminação de preços}

\section{1. \\ Dispersão de preços: possíveis explicações}

Na teoria econômica, há algumas explicações para o fenômeno empírico de dispersão de preços de passagens aéreas de uma empresa em uma rota. De acordo com Puller et al. (2009), essas explicações podem ser classificadas em dois grupos de modelos: discriminação de preços e scarcity pricing. Uma discussão conceitual sobre cada grupo é feita a seguir.

Em modelos de discriminação de preços de segundo grau, uma firma se depara com consumidores heterogêneos, mas não é capaz de distingui-los. Oferecendo várias alternativas aos consumidores, a firma procura induzir a autosseleção. No caso das companhias aéreas, são oferecidas passagens que diferem em algumas características, como dia e horário do voo, antecedência requerida para a compra, exigência de tempo de permanência no destino e taxas de cancelamento e alteração. Os preços e as características das passagens são estabelecidos de maneira a fazer com que os consumidores com maior disposição a pagar comprem as passagens mais caras. Assim, a discriminação de preços requer, por exemplo, que passagens compradas com pouca antecedência tenham preços maiores. Os viajantes a trabalho, com maior disposição a pagar, não conseguem, em geral, comprar passagens com muita antecedência. São, majoritariamente, os viajantes a lazer, com menor disposição a pagar, que compram com antecedência e se aproveitam dos preços menores. É possível empregar a antecedência da compra para discriminar preços porque as passagens aéreas são nominais e intransferíveis, o que impede a arbitragem.

Os modelos de scarcity pricing proveem explicações alternativas para a dispersão de preços. Em modelos como o de Dana (1999) e o de Gale \& Holmes (1993), diferenças nos preços de duas passagens de uma empresa em uma rota refletem diferenças de custo associadas à escassez. No modelo de Dana (1999), herdeiro das contribuições de Prescott (1975) e Eden (1990), determinam-se 
preços e quantidades de passagens em um voo. As passagens são homogêneas, mas ainda assim há dispersão de preços em equilíbrio. Duas hipóteses do modelo de Dana (1999) são responsáveis por gerar dispersão de preços. A demanda é estocástica e há um custo de capacidade, que pode ser interpretado como o custo marginal de um assento em uma aeronave, incorrido estando o assento ocupado ou desocupado. A intuição para haver dispersão de preços em equilíbrio é a seguinte: a maximização de lucro requer que a empresa tenha passagens suficientes para atender à demanda quando ela é alta; passagens que serão vendidas somente nos estados em que a demanda é alta devem ter um preço maior para cobrir o custo de capacidade incorrido nos estados em que não serão vendidas. Uma implicação do modelo de Dana (1999), segundo Puller et al. (2009), é que o preço que um consumidor paga pela passagem deve ser positivamente correlacionado com o número de passagens já vendidas para o voo. Isso porque, como as passagens são homogêneas, cada consumidor escolhe a de menor preço disponível, o que faz com que as passagens sejam transacionadas na ordem de seus preços.

Ainda no âmbito de scarcity pricing, Gale \& Holmes (1993) desenvolvem um modelo com restrição de capacidade. Uma companhia aérea possui dois voos em uma rota, sendo que em um deles - o voo no horário de pico - a demanda excede a capacidade da aeronave. Gale \& Holmes (1993) mostram que é ótimo, para a empresa, oferecer descontos em passagens compradas com antecedência para o voo fora do horário de pico. A dispersão de preços é, assim, uma forma de ajustar a demanda à capacidade. O preço com desconto para o voo fora do horário de pico reflete o menor custo de oportunidade de vender passagens para esse voo.

\section{2.}

Regressões em forma reduzida

Para investigar se há evidência de discriminação de preços de passagens aéreas no mercado brasileiro, utilizam-se regressões em forma reduzida. Havendo discriminação de preços, os dados devem mostrar passageiros com maior renda e que viajam a trabalho pagando preços maiores. Como esse padrão nos dados também pode ser explicado por modelos de scarcity pricing, busca-se controlar por variáveis que captem a influência da escassez sobre os preços. 
As regressões são apresentadas na Tabela 2. Nas colunas (1) a (4), são utilizados efeitos fixos de rota-companhia aérea. Sem mais controles além dos efeitos fixos, um aumento de $1 \%$ na renda está associado a um preço $3.9 \%$ maior; passageiros que viajam a trabalho pagam $33 \%$ a mais. Os dois coeficientes de interesse são significativos a $1 \%$.

Discriminação de preços não é a única explicação possível para os coeficientes de $\log ($ renda) e trabalho mostrados na coluna (1). Pode ser que passageiros com maior renda e que viajam a trabalho voem, predominantemente, em horários de pico, nos quais, de acordo com o modelo de scarcity pricing de Gale \& Holmes (1993), os preços médios são maiores porque as empresas enfrentam restrições de capacidade. Inserindo, na coluna (2), dummies de dia da semana e de horário do voo, os coeficientes de interesse não têm alterações relevantes.

Os resultados das regressões nas colunas (1) e (2) também podem ser explicados pelo modelo de scarcity pricing de Dana (1999), se passageiros com maior renda e que viajam a trabalho adquirem passagens quando os voos estão quase cheios. Assim, o ideal seria utilizar como controle a parcela de assentos no voo já vendidos quando o consumidor adquiriu sua passagem. Como não dispomos desse dado, incluímos o número de semanas completas entre a compra da passagem e o voo (variável antecedência) e construímos uma proxy. Para um passageiro na rota $r$ que adquiriu a passagem com $t$ dias de antecedência, a proxy é o produto entre a ocupação de seu voo na decolagem e a proporção de passageiros na rota $r$ que adquiriu a passagem com mais de $t$ dias de antecedência.

Incluindo antecedência na regressão da coluna (3), o coeficiente de trabalho reduz-se em aproximadamente um terço e permanece significativo a $1 \%$. Uma vez que se controla por antecedência, inserir a proxy para ocupação praticamente não altera os coeficientes de interesse.

É possível que as dummies de dia da semana e de horário não captem o horário de pico ou não sejam suficientes para controlar por diferenças de custos entre voos de uma companhia aérea em uma rota. Por isso, na coluna (5), utilizam-se efeitos fixos de voo, sendo um voo definido por seu número, aeroportos de origem e destino e sua data. Empregando efeitos fixos de voo, os 
coeficientes de interesse têm uma pequena redução e mantêm-se significativos estatística e economicamente.

A inclusão de vários controles permite afirmar que os coeficientes de $\log ($ renda) e trabalho na coluna (5) captam discriminação de preços. Isso não exclui a possibilidade de que parte da dispersão de preços seja explicada por scarcity pricing. Porém, o que se pode extrair das regressões é que há evidência de discriminação de preços.

Tabela 2 - Regressões em forma reduzida

Variável dependente: $\log ($ preço)

\begin{tabular}{lccccc}
\hline & $(1)$ & $(2)$ & $(3)$ & $(4)$ & $(5)$ \\
\hline $\log ($ renda) & 0.039 & 0.040 & 0.039 & 0.039 & 0.033 \\
& $(0.005)$ & $(0.005)$ & $(0.004)$ & $(0.004)$ & $(0.006)$ \\
trabalho & 0.330 & 0.325 & 0.219 & 0.221 & 0.214 \\
& $(0.010)$ & $(0.010)$ & $(0.010)$ & $(0.010)$ & $(0.012)$ \\
antecedência & & & -0.120 & -0.092 & -0.071 \\
& & & $(0.003)$ & $(0.005)$ & $(0.008)$ \\
proxy para ocupação & & & & 0.245 & 0.374 \\
& & & & $(0.035)$ & $(0.054)$ \\
Dummies de dia da semana (6) & & Sim & Sim & Sim & \\
Dummies de faixa de horário (11) & & Sim & Sim & Sim & \\
Efeitos fixos de rota-cia.aérea (262) & Sim & Sim & Sim & Sim & \\
Efeitos fixos de voo (3284) & & & & & Sim \\
Constante & Sim & Sim & Sim & Sim & Sim \\
Observações & 11993 & 11993 & 11993 & 11993 & 11993 \\
$\mathrm{R}^{2}$ ajustado & 0.342 & 0.342 & 0.416 & 0.418 & 0.441 \\
\hline Notas: (1) Estimação por mínimos quadrados ordinários. (2) & Entre parênteses, desvio padrão robusto à \\
heterocedasticidade. (3) Há, pelo menos, duas observaçóes em cada voo. (4) Cada dummy de faixa de horário \\
indica um intervalo de duas horas. (5) Definições das variáveis estão no Apêndice.
\end{tabular}




\section{4 Um modelo empírico de discriminação de preços}

\section{1.}

Modelo

No modelo, uma firma oferece passagens aéreas para diferentes rotas e voos, as quais podem ser adquiridas com diferentes antecedências. O problema da firma consiste em estabelecer o preço da passagem para a rota $r$, voo $v$, com antecedência $t$ - denotado por $p_{r v t}$ - para toda tripla $(r, v, t)$.

Cada potencial passageiro está vinculado a uma única rota, voo e antecedência. Um potencial passageiro da rota $r$, voo $v$, com antecedência $t$ adquire a passagem se e somente se $W T P \geq p_{r v t}$, em que $W T P$ denota a disposição a pagar. Sua decisão não é afetada por $p_{r v^{\prime} t}$ ou por $p_{r v t^{\prime}}$, para $v^{\prime} \neq v \mathrm{e}$ $t^{\prime} \neq t$

A firma não observa $W T P$, mas conhece $z$, um vetor de atributos da rota, do voo e da antecedência. A firma utiliza $z$ para prever a disposição a pagar dos potenciais passageiros: supõe-se que ela conhece $E(W T P \mid z)$. O termo $\zeta \equiv$ $W T P-E(W T P \mid z)$ não é observado pela firma, mas sua função distribuição acumulada $F(\zeta)$ é conhecida. As realizações de $\zeta$ são independentes entre os potenciais passageiros.

A título de exemplo, tomemos um potencial passageiro da rota $r$, voo $v$, com antecedência $t$. Para prever sua disposição a pagar, a firma utiliza $z_{r v t}$ (o subscrito denota a realização do vetor aleatório $z$ ). Do ponto de vista da firma, a probabilidade desse potencial passageiro adquirir a passagem quando o preço é $p_{r v t}$ é dada por $1-F\left(p_{r v t}-E\left(W T P \mid z_{r v t}\right)\right)$.

Considera-se que o custo marginal de uma passagem é constante, e que seu valor varia por rota. A estrutura dos custos e da demanda implica separabilidade: a firma maximiza o lucro esperado total se e somente se maximiza o lucro que espera obter com passagens para a rota $r$, voo $v$, com antecedência $t$ para toda tripla $(r, v, t)$. 
Denota-se por $p_{r v t}^{*}$ um preço que maximiza o lucro que a firma espera obter com passagens para a rota $r$, voo $v$, com antecedência $t$. Se o custo marginal de uma passagem para a rota $r$ é $c_{r}$, então $p_{r v t}^{*}$ é caracterizado por:

$p_{r v t}^{*} \in \operatorname{argmax}_{p}\left(p-c_{r}\right)\left(1-F\left(p-E\left(W T P \mid z_{r v t}\right)\right)\right)$

A equação (1) explicita o trade-off enfrentado pela firma: um preço maior aumenta o lucro em caso de venda, mas diminui a probabilidade de a venda ocorrer. Está implícito em (1) que $p_{r v t}^{*}$ não depende do número de potenciais passageiros.

Algumas características dos potenciais passageiros, correlacionadas com $W T P$, não são observadas pela firma. Essas variáveis formam o vetor $x^{1}$. Apesar de $x^{1}$ não afetar diretamente o preço das passagens, é possível estimar a relação entre $x^{1}$ e WTP. Para isso, adota-se a seguinte hipótese:

$E\left(W T P \mid x ; z^{1}\right)=E(W T P \mid x)$

em que $x=\left[x^{1} z^{2}\right]$ e $z^{1}$ e $z^{2}$ são tais que $z=\left[z^{1} z^{2}\right]$. A suposição contida em (2) significa que se a firma observasse $x^{1}$, não precisaria de $z^{1}$ para prever a disposição a pagar dos potenciais passageiros.

O modelo não incorpora nenhum elemento de scarcity pricing. Assim, a dispersão de preços de passagens em uma rota é integralmente explicada por discriminação de preços. Dito de outro modo, a diferença de preço entre duas passagens em uma rota reflete a diferença na disposição a pagar dos potenciais passageiros.

No modelo, a firma estabelece seus preços como um monopolista. Trata-se de uma simplificação - dado que há oligopólio nas rotas que fazem parte da aplicação empírica -, mas que nos parece razoável. Caplin \& Nalebuff (1991) mostram que, dados os preços das concorrentes, a demanda de uma firma em um oligopólio pode ser descrita como a demanda de um monopolista que se defronta com consumidores cuja decisão de compra é representada por uma abordagem de disposição a pagar. Embora a forma como modelamos a disposição a pagar difira daquela desenvolvida em Caplin \& Nalebuff (1991), consideramos que o modelo incorpora as principais forças econômicas que afetam a precificação de uma companhia aérea que discrimina preços, mesmo que ela atue em um mercado oligopolizado. 


\section{2. \\ Resolução}

Apresenta-se, a seguir, a resolução do modelo, feita a partir da imposição de uma distribuição para $\zeta$ e de parametrizações para o custo marginal e para as esperanças condicionais.

Supõe-se que $E(W T P \mid z)$ e $E(W T P \mid x)$ são lineares com vetores de parâmetros $\delta$ e $\beta$, respectivamente. Assim, $E(W T P \mid z)=z \delta$ e $E(W T P \mid x)=x \beta$. No Apêndice, mostra-se que as hipóteses de linearidade, juntamente com (2), implicam a seguinte relação entre $\beta$ e $\delta$ :

$E\left(z^{\prime} x\right) \beta=E\left(z^{\prime} z\right) \delta$

Supõe-se que $\zeta$ segue uma distribuição uniforme no intervalo $[-a, a]$, com $a>0$. O custo marginal é dado por $c_{r}=q_{r} \eta$, em que $q_{r}$ é um vetor de características da rota e $\eta$ um vetor de parâmetros. Sob essa estrutura, $p_{r v t}^{*}$ é caracterizado por:

$p_{r v t}^{*} \in \operatorname{argmax}_{p}\left\{\begin{array}{rr}p-q_{r} \eta & \text { se } p \leq z_{r v t} \delta-a \\ \frac{\left(p-q_{r} \eta\right)\left(a-p+z_{r v t} \delta\right)}{2 a} \text { se } z_{r v t} \delta-a \leq p \leq z_{r v t} \delta+a \\ 0 \quad \text { se } p \geq z_{r v t} \delta+a\end{array}\right.$.

Tem-se, então, que $p_{r v t}^{*}$ é tal que:

$\left\{\begin{array}{lr}p_{r v t}^{*}=z_{r v t} \delta-a & \text { se } z_{r v t} \delta \geq q_{r} \eta+3 a \\ p_{r v t}^{*}=\frac{z_{r v t} \delta+q_{r} \eta+a}{2} & \text { se } q_{r} \eta-a \leq z_{r v t} \delta \leq q_{r} \eta+3 a \\ p_{r v t}^{*} \geq z_{r v t} \delta+a & \text { se } z_{r v t} \delta \leq q_{r} \eta-a\end{array}\right.$

As condições que caracterizam $p_{r v t}^{*}$ em (4) são intuitivas. Para definir $p_{r v t}^{*}$, a firma utiliza sua previsão da disposição a pagar dos potenciais passageiros, dada por $z_{r v t} \delta$. Se $z_{r v t} \delta$ é maior ou igual a um limiar superior, a firma cobra o maior preço ao qual a probabilidade de venda é igual a 1 . Se $z_{r v t} \delta$ é menor ou igual a um limiar inferior, a firma estabelece algum preço que faça com que não venda com certeza, pois os preços aos quais a probabilidade de venda é positiva estão abaixo do custo marginal. Nos casos intermediários, em que $z_{r v t} \delta$ é maior que o limiar inferior e menor que o limiar superior, a firma cobra um preço ao qual a probabilidade de venda está entre 0 e 1. 


\section{3. Estimação}

Utilizam-se dados dos vetores $z, x$ e $q$ e dos preços pagos por passageiros para obter estimativas dos parâmetros $\delta, \eta, a$ e $\beta$. Os três primeiros são estimados diretamente; $\beta$ é estimado indiretamente utilizando a estimativa obtida para $\delta$.

$\mathrm{Na}$ estimação de $\delta, \eta$ e $a$, buscam-se valores para esses parâmetros que aproximem os preços observados dos preços previstos pelo modelo. Observam-se os preços pagos por indivíduos que adquiriram passagens. Por isso, é conveniente excluir a possibilidade - existente no modelo - de a firma estabelecer um preço que torne a probabilidade de venda igual a 0 . Isso equivale à restrição $z_{r v t} \delta \geq$ $q_{r} \eta-a$ para toda tripla $(r, v, t)$ na base de dados. O seguinte problema de minimização com restrições tem como solução $(\hat{\delta}, \hat{\eta}, \hat{a})$ :

$\begin{cases}\min _{\delta, \eta, a} \Sigma_{i}\left(p_{\text {irvt }}-p_{r v t}^{*}\right)^{2} & \\ \text { sujeito } a & z_{r v t} \delta \geq q_{r} \eta-a \forall(r, v, t) \\ a>0\end{cases}$

Em (5), $i$ indexa as observações, $p_{\text {irvt }}$ denota o preço pago pelo indivíduo $i$ por uma passagem para a rota $r$, voo $v$, com antecedência $t$ e $p_{r v t}^{*}$ é dado por:

$p_{r v t}^{*}= \begin{cases}z_{r v t} \delta-a & \text { se } z_{r v t} \delta \geq q_{r} \eta+3 a \\ \frac{z_{r v t} \delta+q_{r} \eta+a}{2} & \text { se } z_{r v t} \delta \leq q_{r} \eta+3 a\end{cases}$

Cabe notar, em (6), que os vetores $z$ e $q$ afetam $p_{r v t}^{*}$ de maneira diferente, o que contribui para identificação de $\delta$ e $\eta$. Isso é importante porque, na especificação econométrica, algumas variáveis que exercem efeito sobre a disposição a pagar são altamente correlacionadas com variáveis que afetam os custos.

Para estimar $\beta$, emprega-se a relação entre $\beta$ e $\delta$ descrita em (3). Substituindo $\delta$ por $\hat{\delta}$ e os operadores esperança por médias amostrais, tem-se um sistema de equações lineares para $\beta$. Nos casos em que a dimensão do vetor $z$ é maior que a dimensão de $x$ e o sistema não possui solução, utiliza-se a matriz pseudoinversa de Moore-Penrose para obter o vetor $\beta$ que minimiza a soma dos quadrados dos desvios das equações ${ }^{7}$.

\footnotetext{
${ }^{7}$ No sistema de equações lineares $A x=b$, se $x^{*}=A^{+} b$, em que $A^{+}$denota a matriz pseudoinversa, então $x^{*} \in \operatorname{argmin}_{x}(A x-b)^{\prime}(A x-b)$.
} 


\section{4. \\ Especificação econométrica}

Como o modelo descreve uma firma que estabelece preços como um monopolista, o ideal seria aplicá-lo a rotas caracterizadas por monopólio. Porém, em agosto de 2009, havia monopólio em apenas 10 rotas da base de dados, e nelas há cerca de 500 observações. Essa limitação dos dados motivou a adoção de uma solução alternativa: concentrar-se em um conjunto de rotas com grau de competição parecido. Foram consideradas rotas envolvendo cidades entre as quais havia, em agosto de 2009, voos diretos das duas empresas com maior participação no mercado doméstico - Tam e Gol - e de, pelo menos, mais um concorrente, entre Webjet, Azul e OceanAir ${ }^{8}$. Nesses critérios, enquadram-se 43 rotas, entre as quais as 10 rotas com maior tráfego de passageiros em 2009.

São apresentadas duas especificações econométricas - (1) e (2). As duas diferem nas variáveis em $z^{1}$ e têm as mesmas variáveis nos vetores $z^{2}, x^{1}$ e $q$. No vetor $z^{2}$, contido em $z=\left[z^{1} z^{2}\right]$ e em $x=\left[x^{1} z^{2}\right]$, estão atributos da rota, do voo e da antecedência que a firma utiliza para prever a disposição a pagar. Fazem parte de $z^{2}$ a distância da rota, uma dummy indicando que Guarulhos é um dos aeroportos da rota e outra indicando que Galeão é um dos aeroportos da rota. A razão para a inclusão dessas duas dummies é que São Paulo e Rio de Janeiro têm dois aeroportos e pode ser que haja, em média, maior disposição a pagar para utilizar um deles. Também pertencem a $z^{2}$ as variáveis dia (dummy indicando que a data do voo é uma terça, quarta ou quinta-feira), horário (dummy indicando que o voo parte entre $7 \mathrm{~h}$ e $10 \mathrm{~h}$ ou entre $17 \mathrm{~h}$ e $20 \mathrm{~h}$ ) e antecedência. No vetor $x^{1}$, de características do passageiro não observadas pela firma, estão as variáveis renda (em $\log$ ) e trabalho. $\mathrm{O}$ vetor de custos $q$ contém as variáveis combustível e saturação - essa última construída com base no grau de utilização da capacidade dos aeroportos da rota.

$\mathrm{Na}$ especificação (1), o vetor $z^{1}$ é formado pelas variáveis renda média rota (em $\log$ ) e trabalho proporção rota, que medem, respectivamente, a média de renda entre os entrevistados na rota e a proporção de entrevistados na rota que viajam a trabalho. Supõe-se que essas variáveis cumprem o requisito de

\footnotetext{
${ }^{8}$ Essas eram, respectivamente, a $3^{\mathrm{a}}, 4^{\mathrm{a}}$ e $5^{\mathrm{a}}$ empresas em termos de participação no mercado doméstico em 2009. Foram considerados apenas passageiros das 5 companhias aéreas mencionadas.
} 
redundância: se a firma soubesse a renda de um indivíduo e se ele é um viajante a trabalho, as médias da rota não ajudariam a prever sua disposição a pagar. Uma hipótese adicional é que a firma conhece, para cada rota, a renda média dos passageiros e a proporção de viajantes a trabalho.

$\mathrm{Na}$ especificação (2), o vetor $z^{1}$ contém 9 variáveis dummy, cada uma indicando uma cidade (a dummy do Rio de Janeiro, por exemplo, é igual a 1 se um dos aeroportos da rota está no Rio de Janeiro). Essa especificação envolve a hipótese de que, levando em conta a distância da rota, as cidades de origem e destino não ajudariam a prever a disposição a pagar caso a firma soubesse a renda do passageiro e se ele é um viajante a trabalho. Além disso, é preciso supor que as dummies de cidade captam somente efeitos sobre a disposição a pagar.

\section{5. Estimativas}

Estimativas dos parâmetros do modelo são apresentadas na Tabela 3. Na especificação (1), o coeficiente de trabalho proporção rota indica que um aumento de 10 pontos percentuais na proporção de viajantes a trabalho na rota aumenta em $\mathrm{R}$ \$ 35 a previsão feita pela firma da disposição a pagar dos potenciais passageiros da rota. A interpretação do coeficiente de antecedência é que potenciais passageiros com antecedência de 4 ou mais semanas têm, na previsão da firma, disposição a pagar $\mathrm{R} \$ 247$ menor que potenciais passageiros com antecedência inferior a uma semana. Em relação às variáveis de custo, o coeficiente de saturação indica que uma rota em que os dois aeroportos têm os sistemas de pista e de pátio saturados (caso de Brasília-Congonhas) apresenta custo marginal $\mathrm{R} \$$ 176 maior do que uma rota em que nenhum dos aeroportos apresenta algum sistema saturado (caso de Curitiba-Porto Alegre). A estimativa para o parâmetro $a$, da distribuição uniforme, significa que a disposição a pagar pode estar até R $\$$ 114 abaixo ou acima da previsão da firma.

$\mathrm{Na}$ especificação (2), em que $z^{1}$ contém dummies de cidade, a estimativa do parâmetro $a$ é praticamente a mesma de (1). A previsão feita pela firma da disposição a pagar é maior para potenciais passageiros de rotas que envolvem São Paulo e Brasília. O coeficiente de saturação se reduz em relação ao obtido em (1) e torna-se estatisticamente não significativo. Isso sugere que as dummies de 
cidade captam efeitos sobre os custos, e não somente efeitos sobre a disposição a pagar. Por essa razão, a especificação (1) é preferida.

Tabela 3 - Estimativas dos parâmetros do modelo

\begin{tabular}{|c|c|c|c|c|c|}
\hline & & \multicolumn{2}{|c|}{ Especificação (1) } & \multicolumn{2}{|c|}{ Especificação (2) } \\
\hline & & coeficiente & $\begin{array}{l}\text { desvio } \\
\text { padrão }\end{array}$ & coeficiente & $\begin{array}{l}\text { desvio } \\
\text { padrão }\end{array}$ \\
\hline & & & inel $A$ : Es & as de $\delta, \eta$ e $a$ & \\
\hline \multirow[t]{11}{*}{$z^{1}$} & log(renda média rota) & 153.49 & $(26.65)$ & & \\
\hline & trabalho proporção rota & 346.95 & $(37.80)$ & & \\
\hline & São Paulo & & & 97.09 & $(9.21)$ \\
\hline & Campinas & & & -87.94 & $(17.22)$ \\
\hline & Rio de Janeiro & & & -24.77 & $(14.69)$ \\
\hline & Belo Horizonte & & & -18.99 & $(10.05)$ \\
\hline & Curitiba & & & -18.64 & $(10.73)$ \\
\hline & Porto Alegre & & & -12.65 & $(11.90)$ \\
\hline & Brasília & & & 59.90 & $(9.57)$ \\
\hline & Salvador & & & -1.32 & $(10.66)$ \\
\hline & Recife & & & 29.37 & $(9.34)$ \\
\hline \multirow[t]{7}{*}{$z^{2}$} & distância & 0.214 & $(0.018)$ & 0.120 & $(0.015)$ \\
\hline & Guarulhos & -46.83 & $(7.03)$ & -119.91 & $(12.42)$ \\
\hline & Galeão & -23.23 & $(7.96)$ & -16.55 & $(20.61)$ \\
\hline & dia & 6.14 & $(4.07)$ & 4.76 & $(3.72)$ \\
\hline & horário & 9.64 & $(4.11)$ & 12.08 & $(4.07)$ \\
\hline & antecedência & -61.85 & $(2.20)$ & -50.04 & $(6.30)$ \\
\hline & constante & -1182.3 & $(201.9)$ & 343.08 & $(21.44)$ \\
\hline \multirow[t]{4}{*}{$q$} & combustível & 6.31 & $(3.72)$ & 11.88 & $(84.56)$ \\
\hline & saturação & 44.02 & $(4.09)$ & -5.54 & (71.01) \\
\hline & $a$ & 113.61 & $(21.52)$ & 113.16 & (20.59) \\
\hline & & \multicolumn{4}{|c|}{ Painel B: Estimativas de $\beta$} \\
\hline \multirow[t]{2}{*}{$x^{1}$} & $\log ($ renda $)$ & 202.99 & $(40.92)$ & 243.22 & $(44.12)$ \\
\hline & trabalho & 274.99 & $(45.55)$ & 248.19 & $(75.00)$ \\
\hline \multirow[t]{7}{*}{$z^{2}$} & distância & 0.250 & $(0.016)$ & 0.243 & $(0.016)$ \\
\hline & Guarulhos & -24.50 & $(8.87)$ & 4.39 & $(15.21)$ \\
\hline & Galeão & -29.49 & $(9.15)$ & -55.32 & $(10.15)$ \\
\hline & dia & -27.65 & $(7.70)$ & -24.65 & $(10.26)$ \\
\hline & horário & -22.33 & $(6.40)$ & -23.48 & $(9.78)$ \\
\hline & antecedência & -32.10 & $(4.40)$ & -20.87 & $(8.51)$ \\
\hline & constante & -1516.2 & $(304.9)$ & -1814.8 & $(355.9)$ \\
\hline
\end{tabular}

Estimado indiretamente, $\beta$ mede o efeito de variáveis não observadas pela firma sobre a disposição a pagar. As estimativas são parecidas nas duas especificações e economicamente plausíveis. Um aumento de $1 \%$ na renda (equivalente, na renda média, a uma elevação de $\mathrm{R} \$ 47$ ) está associado a um incremento de $\mathrm{R}$ \$ 2.03 ou $\mathrm{R}$ \$ 2.43 na disposição a pagar. Viajantes a trabalho têm uma disposição a pagar $\mathrm{R}$ \$ 248 ou $\mathrm{R}$ \$ 275 maior. 
Os coeficientes de dia, horário e antecedência em $\beta$ são significativamente diferentes dos coeficientes dessas variáveis em $\delta$. Isso mostra que essas variáveis são particularmente úteis para a firma prever a disposição a pagar porque captam o efeito indireto de variáveis que ela não observa. O efeito indireto de renda e trabalho responde por aproximadamente metade do coeficiente de antecedência na previsão da disposição a pagar feita pela firma. 


\section{5 Implicações sobre o bem-estar}

\section{1.}

Mensuração

A seguir, são definidas medidas de bem-estar no arcabouço do modelo. Mostra-se como obter medidas agregadas ao nível da rota, o que requer estimar a distribuição dos potenciais passageiros da rota por voo e antecedência.

Denota-se por $E(C S \mid z)$ o valor esperado do excedente do consumidor de um potencial passageiro, uma vez conhecidos os atributos de sua rota, seu voo e sua antecedência. Esse potencial passageiro gera, para a firma, um lucro esperado denotado por $E(\Pi \mid z)$. Se $p$ é o preço cobrado desse potencial passageiro, então:

$E(C S \mid z)=E(W T P-p \mid W T P \geq p ; z) \cdot \operatorname{Pr}(W T P \geq p \mid z)$

$E(\Pi \mid z)=(p-q \eta) \cdot \operatorname{Pr}(W T P \geq p \mid z)$

Com base em (7) e (8), é possível usar a estrutura do modelo para expressar $E(C S \mid z)$ e $E(\Pi \mid z)$ em função de $z, q, p$ e dos parâmetros $\delta, \eta$ e $a$. Deriva-se, no Apêndice, uma expressão para $E(W T P-p \mid W T P \geq p ; z)$.

Para definir medidas de bem-estar agregadas ao nível da rota, particiona-se o vetor $z$ em $z=\left[z^{R} z^{V T}\right]$. As variáveis no vetor $z^{R}$ são atributos da rota; $z^{V T}$ contém atributos do voo e da antecedência. Os objetos de interesse são $E\left(C S \mid z^{R}\right)$ e $E\left(\Pi \mid z^{R}\right)$, que denotam, respectivamente, o excedente do consumidor e o lucro esperados, conhecidos apenas os atributos da rota. Considerando que $z^{V T}$ toma valores no conjunto finito $\mathcal{S}$, emprega-se a Lei das Expectativas Iteradas:

$$
\begin{aligned}
& E\left(C S \mid z^{R}\right)=\Sigma_{s \in \mathcal{S}} E\left(C S \mid z^{V T}=s ; z^{R}\right) \cdot \operatorname{Pr}\left(z^{V T}=s \mid z^{R}\right) \\
& E\left(\Pi \mid z^{R}\right)=\Sigma_{s \in \mathcal{S}} E\left(\Pi \mid z^{V T}=s ; z^{R}\right) \cdot \operatorname{Pr}\left(z^{V T}=s \mid z^{R}\right)
\end{aligned}
$$

As equações (9) e (10) explicitam que $E\left(C S \mid z^{R}\right)$ e $E\left(\Pi \mid z^{R}\right)$ dependem da distribuição dos potenciais passageiros da rota, isto é, de $\operatorname{Pr}\left(z^{V T}=s \mid z^{R}\right)$ $\forall s \in \mathcal{S}$. Tais probabilidades, porém, não são diretamente obtidas a partir dos parâmetros do modelo. A fim de estimar $\operatorname{Pr}\left(z^{V T}=s \mid z^{R}\right) \forall s \in \mathcal{S}$, expressam-se essas probabilidades em função de um objeto estimável nos dados e de outro que 
depende dos parâmetros do modelo. Para isso, denota-se por compra o evento "potencial passageiro adquire passagem" e seja $w \in \mathcal{S}$. Pelo Teorema de Bayes:

$\operatorname{Pr}\left(z^{V T}=w \mid\right.$ compra $\left.; z^{R}\right)=\frac{\operatorname{Pr}\left(\text { compra } \mid z^{V T}=w ; z^{R}\right) \cdot \operatorname{Pr}\left(z^{V T}=w \mid z^{R}\right)}{\sum_{s \in \mathcal{S}} \operatorname{Pr}\left(\text { compra } \mid z^{V T}=s ; z^{R}\right) \cdot \operatorname{Pr}\left(z^{V T}=s \mid z^{R}\right)}$.

Seja $w^{\prime} \in \mathcal{S}, w^{\prime} \neq w, \operatorname{com} \operatorname{Pr}\left(z^{V T}=w^{\prime} \mid \operatorname{compra} ; z^{R}\right) \neq 0$ :

$\frac{\operatorname{Pr}\left(z^{V T}=w \mid \text { compra } ; z^{R}\right)}{\operatorname{Pr}\left(z^{V T}=w^{\prime} \mid \text { compra } ; z^{R}\right)}=\frac{\operatorname{Pr}\left(\text { compra } \mid z^{V T}=w ; z^{R}\right)}{\operatorname{Pr}\left(\text { compra } \mid z^{V T}=w^{\prime} ; z^{R}\right)} \cdot \frac{\operatorname{Pr}\left(z^{V T}=w \mid z^{R}\right)}{\operatorname{Pr}\left(z^{V T}=w^{\prime} \mid z^{R}\right)}$

É possível expressar $\operatorname{Pr}\left(z^{V T}=w \mid z^{R}\right)$ como:

$\operatorname{Pr}\left(z^{V T}=w^{\prime} \mid z^{R}\right) \cdot \frac{\operatorname{Pr}\left(z^{V T}=w \mid \text { compra } ; z^{R}\right)}{\operatorname{Pr}\left(z^{V T}=w^{\prime} \mid \text { compra } ; z^{R}\right)} \cdot \frac{\operatorname{Pr}\left(\operatorname{compra} \mid z^{V T}=w^{\prime} ; z^{R}\right)}{\operatorname{Pr}\left(\operatorname{compra} \mid z^{V T}=w ; z^{R}\right)}$

A equação (11) mostra que estimar $\operatorname{Pr}\left(z^{V T}=s \mid z^{R}\right) \forall s \in \mathcal{S}$ passa por estimar $\operatorname{Pr}\left(z^{V T}=s \mid\right.$ compra; $\left.z^{R}\right)$ e $\operatorname{Pr}\left(\right.$ compra $\left.\mid z^{V T}=s ; z^{R}\right) \forall s \in \mathcal{S}$. Como a base de dados é formada por indivíduos que adquiriram passagens, ela é empregada para estimar $\operatorname{Pr}\left(z^{V T}=s \mid\right.$ compra; $\left.z^{R}\right)$. Para uma dada rota, toma-se a proporção de observações para as quais $z^{V T}=s$. A fim de estimar $\operatorname{Pr}\left(\right.$ compra $\left.\mid z^{V T}=s ; z^{R}\right)$, utiliza-se a estrutura do modelo. Se a realização de $z^{R}$ é dada pelos atributos da rota $r$ e se $s$ são os atributos do voo $v$, com antecedência $t$, calcula-se a probabilidade de um potencial passageiro adquirir a passagem ao preço $p_{r v t}^{*}$, condicional a $z_{r v t}$. No cálculo da probabilidade, usam-se os parâmetros estimados no modelo.

A estimação da distribuição dos potenciais passageiros da rota permite obter $E\left(C S \mid z^{R}\right)$ e $E\left(\Pi \mid z^{R}\right)$. Além disso, é possível calcular $\operatorname{Pr}\left(W T P \geq p \mid z^{R}\right)$. Aplicando a Lei das Expectativas Iteradas:

$\operatorname{Pr}\left(W T P \geq p \mid z^{R}\right)=\Sigma_{s \in \mathcal{S}} \operatorname{Pr}\left(W T P \geq p \mid z^{V T}=s ; z^{R}\right) \cdot \operatorname{Pr}\left(z^{V T}=s \mid z^{R}\right)$

A Figura 2, no Apêndice, mostra a relação entre $\operatorname{Pr}\left(W T P \geq p \mid z^{R}\right)$ e $p$ para as 5 rotas com maior tráfego de passageiros em 2009. Essa relação é não linear, diferentemente da relação entre $\operatorname{Pr}(W T P \geq p \mid z)$ e $p$.

\section{2.}

\section{Exercícios contrafactuais}

Teoricamente, a discriminação de preços pode gerar ganho ou perda de bem-estar social. O lucro é maior sob discriminação de preços do que sob preço único, mas o excedente do consumidor pode ser maior ou menor. Busca-se avaliar, empregando as estimativas dos parâmetros do modelo, se haveria aumento 
ou redução de bem-estar social caso houvesse restrições sobre a discriminação de preços.

Consideram-se cenários contrafactuais em que a firma tem menor capacidade de discriminar preços, não podendo variar os preços por rota, voo e antecedência. Em um exercício contrafactual, a firma deve cobrar um preço único por rota. Sob essa restrição, o preço que maximiza o lucro esperado da firma na rota $r$ é denotado por $p_{r}^{*}$ e dado por:

$p_{r}^{*}=\operatorname{argmax}_{p}\left(p-q_{r} \eta\right) \Sigma_{s \in \mathcal{S}} \operatorname{Pr}\left(W T P \geq p \mid z^{V T}=s ; z_{r}^{R}\right) \cdot \operatorname{Pr}\left(z^{V T}=s \mid z_{r}^{R}\right)$, em que $z_{r}^{R}$ é a realização do vetor aleatório $z^{R}$ para a rota $r$. Em outro exercício contrafactual, a firma cobra preços diferentes em voos da mesma rota, mas o preço não pode variar com a antecedência. Nesse caso, denota-se por $p_{r v}^{*}$ o preço que maximiza o lucro que a firma espera obter com passagens na rota $r$, voo $v$. Sejam $z^{V}$ e $z^{T}$ tais que $z^{V T}=\left[z^{V} z^{T}\right]$, em que $z^{V}$ e $z^{T}$ contém, respectivamente, atributos do voo e da antecedência. Tem-se que:

$p_{r v}^{*}=$

$\operatorname{argmax}_{p}\left(p-q_{r} \eta\right) \Sigma_{h \in \mathcal{H}} \operatorname{Pr}\left(W T P \geq p \mid z^{T}=h ; z_{v}^{V} ; z_{r}^{R}\right) . \operatorname{Pr}\left(z^{T}=h \mid z_{v}^{V} ; z_{r}^{R}\right)$,

em que $z^{T}$ toma valores no conjunto finito $\mathcal{H}$ e $z_{v}^{V}$ é a realização do vetor aleatório $z^{V}$ para o voo $v^{9}$.

Na Tabela 4, é mostrada uma comparação, feita com base nos parâmetros estimados na especificação (1), entre os preços vigentes no modelo e os preços que vigorariam em cada cenário contrafactual. Se os preços variassem apenas por rota e voo, haveria, em geral, um aumento substancial do menor preço para a rota e uma redução pequena - em alguns casos, manutenção - do maior preço para a rota. Caso a firma cobrasse um valor único por rota, esse seria, em geral, próximo ao maior preço para a rota no modelo. Na rota Congonhas-Santos Dumont, por exemplo, o preço único seria $\mathrm{R} \$ 364$. Esse valor, comparado aos preços vigentes no modelo, é próximo aos $\mathrm{R} \$ 371$ cobrados dos passageiros com maior disposição a pagar prevista pela firma e situa-se bem acima dos $R \$ 240$ com que se defrontam os passageiros com menor disposição a pagar prevista pela firma.

Os exercícios contrafactuais sugerem que a discriminação de preços principalmente, por meio da antecedência - torna lucrativo à firma oferecer

\footnotetext{
${ }^{9}$ Procedimento análogo ao descrito para estimar $\operatorname{Pr}\left(z^{V T}=s \mid z^{R}\right) \forall s \in \mathcal{S}$ é empregado para estimar $\operatorname{Pr}\left(z^{T}=h \mid z^{V} ; z^{R}\right) \forall h \in \mathcal{H}$.
} 
algumas passagens a preços reduzidos. Tal conclusão se aplica não apenas às 10 rotas que constam da Tabela 4, mas também às demais. A constatação permanece válida se são empregados os parâmetros estimados na especificação (2) (ver Tabelas 6 e 7, no Apêndice).

Tabela 4 - Preços (em $R \$$ ) no modelo e nos contrafactuais

\begin{tabular}{|c|c|c|c|c|c|}
\hline & \multicolumn{5}{|c|}{ Preços variam por } \\
\hline & \multicolumn{2}{|c|}{$\begin{array}{l}\text { rota, voo e antecedência } \\
\text { (modelo) }\end{array}$} & \multicolumn{2}{|c|}{$\begin{array}{c}\text { rota e voo } \\
\text { (contrafactual) }\end{array}$} & \multirow[t]{2}{*}{$\begin{array}{c}\text { rota } \\
\text { (contrafactual) }\end{array}$} \\
\hline & $\min$ & $\max$ & $\min$ & $\max$ & \\
\hline CGH-SDU & 240 & 371 & 352 & 368 & 364 \\
\hline BSB-CGH & 313 & 459 & 443 & 459 & 452 \\
\hline GRU-SSA & 243 & 388 & 310 & 388 & 378 \\
\hline GRU-REC & 299 & 532 & 454 & 470 & 455 \\
\hline GRU-POA & 163 & 295 & 275 & 291 & 281 \\
\hline $\mathrm{CGH}-\mathrm{CNF}$ & 233 & 394 & 378 & 394 & 382 \\
\hline BSB-GIG & 215 & 348 & 277 & 348 & 338 \\
\hline GIG-SSA & 208 & 370 & 292 & 370 & 299 \\
\hline CGH-CWB & 213 & 359 & 343 & 359 & 353 \\
\hline CGH-POA & 237 & 395 & 327 & 395 & 379 \\
\hline
\end{tabular}

A variação percentual das medidas de bem-estar entre cada cenário contrafactual e o modelo é mostrada nas Tabelas 5,8 e 9 - as duas últimas encontram-se no Apêndice. Os resultados apontam que restrições sobre a discriminação de preços reduziriam $E\left(C S \mid z^{R}\right)$ para quase todas as rotas. Empregados os parâmetros estimados na especificação (1), $E\left(C S \mid z^{R}\right)$ seria, em média, $11 \%$ menor se os preços variassem somente por rota e voo e $14 \%$ menor se os preços variassem apenas por $\operatorname{rota}^{10}$. Números parecidos são obtidos ao se empregar os parâmetros estimados na especificação (2) (ver Tabela 9).

Em relação a $E\left(\Pi \mid z^{R}\right)$, a magnitude da redução seria praticamente a mesma nos dois contrafactuais. Isso significa que a impossibilidade de variar preço com a antecedência responderia pela maior parte da diminuição do lucro da firma.

Conclui-se que o bem-estar social, definido como a soma de $E\left(C S \mid z^{R}\right)$ e $E\left(\Pi \mid z^{R}\right)$, seria menor caso houvesse restrições sobre a discriminação de preços.

${ }^{10}$ Médias da variação de $E\left(C S \mid z^{R}\right)$ entre todas as rotas utilizadas na estimação, exceto GRU-SDU. Para essa rota, não foi possível estimar $\operatorname{Pr}\left(z^{V T}=s \mid z^{R}\right) \forall s \in \mathcal{S}$. 
Com base nos parâmetros estimados na especificação (1), a redução seria, em média, de $11 \%$ ou $13 \%$, dependendo da restrição.

Tabela 5 - Variação percentual das medidas de bem-estar entre cada contrafactual e o modelo

\begin{tabular}{|c|c|c|c|c|c|c|}
\hline & \multicolumn{6}{|c|}{ Contrafactual } \\
\hline & \multicolumn{3}{|c|}{ Preços variam por rota e voo } & \multicolumn{3}{|c|}{ Preços variam por rota } \\
\hline & $E\left(C S \mid z^{R}\right)$ & $E\left(\Pi \mid z^{R}\right)$ & $\begin{array}{r}E\left(C S \mid z^{R}\right) \\
+E\left(\Pi \mid z^{R}\right)\end{array}$ & $E\left(C S \mid z^{R}\right)$ & $E\left(\Pi \mid z^{R}\right)$ & $\begin{array}{r}E\left(C S \mid z^{R}\right) \\
+E\left(\Pi \mid z^{R}\right)\end{array}$ \\
\hline CGH-SDU & $-9 \%$ & $-5 \%$ & $-6 \%$ & $-13 \%$ & $-6 \%$ & $-8 \%$ \\
\hline BSB-CGH & $-25 \%$ & $-9 \%$ & $-14 \%$ & $-25 \%$ & $-10 \%$ & $-15 \%$ \\
\hline GRU-SSA & $-8 \%$ & $-15 \%$ & $-13 \%$ & $-31 \%$ & $-17 \%$ & $-22 \%$ \\
\hline GRU-REC & $-8 \%$ & $-17 \%$ & $-15 \%$ & $-3 \%$ & $-17 \%$ & $-14 \%$ \\
\hline GRU-POA & $-22 \%$ & $-14 \%$ & $-17 \%$ & $-22 \%$ & $-15 \%$ & $-17 \%$ \\
\hline CGH-CNF & $-28 \%$ & $-10 \%$ & $-15 \%$ & $-26 \%$ & $-10 \%$ & $-15 \%$ \\
\hline BSB-GIG & $-4 \%$ & $-14 \%$ & $-11 \%$ & $-27 \%$ & $-16 \%$ & $-19 \%$ \\
\hline GIG-SSA & $-6 \%$ & $-15 \%$ & $-13 \%$ & $+1 \%$ & $-16 \%$ & $-11 \%$ \\
\hline CGH-CWB & $-21 \%$ & $-7 \%$ & $-12 \%$ & $-23 \%$ & $-8 \%$ & $-12 \%$ \\
\hline CGH-POA & $-24 \%$ & $-13 \%$ & $-17 \%$ & $-29 \%$ & $-14 \%$ & $-19 \%$ \\
\hline
\end{tabular}




\section{6 Conclusão}

Os resultados da dissertação indicam que há discriminação de preços de passagens aéreas no mercado brasileiro e que isso tem um impacto positivo sobre o bem-estar social. Evidências de discriminação de preços são obtidas por meio de regressões em forma reduzida. $\mathrm{O}$ uso de vários controles permite concluir que os preços maiores pagos por passageiros com maior renda e passageiros que viajam a trabalho são explicados, em parte, por discriminação de preços. A constatação de que a discriminação de preços é socialmente benéfica deriva da estimação de um modelo empírico. Exercícios contrafactuais apontam que restringir a discriminação de preços não apenas reduziria o lucro, mas também diminuiria o excedente do consumidor.

O modelo incorpora características dos consumidores não observadas pela companhia aérea - caso das variáveis renda e trabalho. Em trabalhos futuros, uma extensão interessante seria utilizar essas variáveis para prever a probabilidade de um potencial passageiro adquirir a passagem. A ideia, na notação do modelo, seria estimar $\operatorname{Pr}(W T P \geq p \mid x)$. Para isso, seria necessário impor mais estrutura sobre o modelo - em particular, sobre a distribuição de $\varepsilon \equiv W T P-x \beta$.

Outra extensão que se vislumbra seria relaxar algumas hipóteses simplificadoras do modelo. Parece-nos viável incorporar no modelo a escolha do consumidor entre diferentes voos, modelando essa escolha como dependente de atributos do voo, como dia, horário e companhia aérea. Embora essa extensão torne o modelo bem mais complexo, traz a possibilidade de avaliar como o padrão de substituição entre voos e a competição entre companhias aéreas afetam a discriminação de preços. 


\section{7 \\ Referências bibliográficas}

ANAC. Anuário do Transporte Aéreo 2009. 2. ed. Brasília, 2010.

_. Relatório de Tarifas Aéreas. 21. ed. Brasília, 2011.

BORENSTEIN, S.; ROSE, N. Competition and Price Dispersion in the U.S. Airline Industry. Journal of Political Economy, v.102, n.4, p.653-683, 1994.

CAPLIN, A.; NALEBUFF, B. Aggregation and Imperfect Competition: on the Existence of Equilibrium. Econometrica, v.59, n.1, p.25-59, 1991.

DAC. Anuário do Transporte Aéreo 2000 - Dados Estatísticos. Rio de Janeiro, 2001.

DANA, J. Equilibrium Price Dispersion Under Demand Uncertainty: the Roles of Costly Capacity and Market Structure. RAND Journal of Economics, v.30, n.4, p.632-660, 1999.

EDEN, B. Marginal Cost Pricing When Spot Markets Are Complete. Journal of Political Economy, v.98, n.6, p.1293-1306, 1990.

ESCOBARI, D.; GAN, L. Price Dispersion Under Costly Capacity and Demand Uncertainty. NBER Working Paper, n. 13075, 2007.

GALE, I.; HOLMES, T. Advance-Purchase Discounts and Monopoly Allocation of Capacity. The American Economic Review, v.83, n.1, p.135-146, 1993. 
GERARDI, K.; SHAPIRO, A. Does Competition Reduce Price Dispersion? New Evidence from the Airline Industry. Journal of Political Economy, v.117, n.1, p.1-37, 2009.

LAZAREV, J. The Welfare Effects of Intertemporal Price Discrimination: an Empirical Analysis of Airline Pricing in U.S. Monopoly Markets. In: LAZAREV, J. Dynamic Pricing in the Airline Industry. Ph.D. Dissertation, Graduate School of Business, Stanford University, 2012.

MCKINSEY \& COMPANY. Estudo do Setor de Transporte Aéreo do Brasil. 1. ed. Rio de Janeiro, 2010.

OLIVEIRA, A. et al. Estudo da Precificação de Companhias Aéreas em Rotas Domésticas de Longo Percurso. Engevista, v.8, n.1, p.4-15, 2006.

PRESCOTT, E. Efficiency of the Natural Rate. Journal of Political Economy, v.83, n.6, p.1229-1236, 1975.

PULLER, S.; TAYLOR, L. Price Discrimination by Day-of-Week of Purchase: Evidence from the U.S. Airline Industry. Journal of Economic Behavior and Organization, v.84, n.3, p.801-812, 2012.

PUlleR, S.; SENGUPTA, A.; WIGGINS, S. Testing Theories of Scarcity Pricing in the Airline Industry. NBER Working Paper, n.15555, 2009.

ROCHLIN, G. Discriminação de Preço nas Companhias Aéreas Brasileiras. Monografia de Final de Curso, Departamento de Economia, Pontifícia Universidade Católica do Rio de Janeiro, 2011.

STAVINS, J. Price Discrimination in the Airline Market: the Effect of Market Concentration. Review of Economics and Statistics, v.83, n.1, p.200-202, 2001. 


\section{8 Apêndice}

\section{1. \\ Dados}

\subsection{1.}

Definição das variáveis

Preço: Variável construída a partir das respostas à seguinte questão da Pesquisa O/D: "Quanto custou a sua passagem aérea deste trecho da viagem (individual, somente a sua, incluindo a taxa de embarque)?". Cabia aos entrevistadores registrar se o valor reportado era referente a um único trecho da viagem ou ao valor total pago nos trechos de ida e volta. Preço é metade do valor reportado caso o passageiro tenha informado o valor total pago nos trechos de ida e volta. $\mathrm{O}$ valor reportado foi desconsiderado nos seguintes casos: (i) não houve registro se era referente a 1 ou 2 trechos; (ii) valor reportado em moeda diferente do real; (iii) indivíduo informou que a passagem foi paga com pontos acumulados no programa de milhagem; (iv) valor reportado igual a 0 . Para contornar o que parecem ter sido erros de registro, não foram considerados preços superiores a $\mathrm{R} \$$ 2 mil.

Renda: Variável definida como a razão entre a renda mensal familiar e o número de pessoas que dependem dela. Renda mensal familiar construída a partir das respostas a duas questões da Pesquisa O/D: "Qual é a sua renda mensal familiar?" (questão aberta, destinada a todos os entrevistados) e "Classe de renda mensal familiar?" (questão com 8 alternativas de resposta, destinada somente aos que não informaram a renda mensal familiar na questão aberta). Na questão aberta, o valor reportado para a renda mensal familiar foi: (i) desconsiderado, se igual a 0; (ii) convertido para real por meio da taxa de câmbio comercial de compra média de agosto de 2009, caso informado em moeda diferente do real. Nos casos em que os entrevistados não reportaram sua renda mensal familiar na questão aberta, mas indicaram uma faixa, entre as 8 apresentadas, tomou-se como renda mensal familiar: (i) o ponto médio da faixa, se essa tinha um limite superior; 
(ii) o valor de $\mathrm{R} \$ 40348$, se a faixa indicada era "acima de $\mathrm{R} \$ 23251$ ” ( $\mathrm{R} \$ 40348$ é a média da renda mensal familiar entre passageiros em itinerários domésticos diretos que reportaram na questão aberta renda mensal familiar superior a $R \$$ 23251). O número de pessoas que dependem da renda mensal familiar foi obtido a partir da resposta à seguinte questão da Pesquisa O/D: "Incluindo o Sr. (a), quantas pessoas dependem desta renda?".

Trabalho: Variável dummy construída a partir das respostas à seguinte questão da Pesquisa O/D: "Quem pagou pela compra de sua passagem aérea deste trecho da viagem?". Trabalho é igual a 1 se o entrevistado escolheu a alternativa "empresa ou órgão em que trabalha".

Antecedência: Variável construída a partir das respostas à seguinte questão da Pesquisa O/D: "Com que antecedência adquiriu a passagem aérea?". Antecedência é igual a: (i) 0 , se o número de dias reportado é inferior a 7; (ii) 1, se o número de dias reportado é maior ou igual a 7 e inferior a 14; (iii) 2 , se o número de dias reportado é maior ou igual a 14 e inferior a 21; (iv) 3, se o número de dias reportado é maior ou igual a 21 e inferior a 28 ; (v) 4, se o número de dias reportado é maior ou igual a 28.

Proxy para ocupação: Variável construída a partir de: (i) dados fornecidos pela Anac relativos à ocupação do voo na decolagem, definida como a razão entre o número de passageiros pagos transportados e a quantidade de assentos da aeronave; (ii) respostas à seguinte questão da Pesquisa O/D: "Com que antecedência adquiriu a passagem aérea?". Para cada indivíduo na base de dados, calculou-se a proporção de entrevistados na mesma rota que adquiriu a passagem com mais dias de antecedência. A variável é definida como o produto entre a ocupação do voo na decolagem e a proporção de passageiros na rota que adquiriu a passagem com mais dias de antecedência.

Distância: Variável construída a partir de dados fornecidos pela Anac e definida como a distância, em quilômetros, entre os aeroportos da rota. Para contornar o que parecem ser erros de tabulação, tomou-se a moda das distâncias registradas nos voos da rota que ocorreram entre 30/07/2009 e 31/08/2009.

Dia: Variável dummy que indica que a data estabelecida para a partida do voo é uma terça-feira, quarta-feira ou quinta-feira. 
Horário: Variável dummy que indica que o horário estabelecido para a partida do voo situa-se entre $7 \mathrm{~h}$ (inclusive) e 10h (exclusive) ou entre $17 \mathrm{~h}$ (inclusive) e 20h (exclusive).

Combustível: Variável construída a partir de dados fornecidos pela Anac e definida como a média de consumo de combustível, em mil litros, nos voos da rota ocorridos entre 30/07/2009 e 31/08/2009.

Saturação: Variável construída a partir de estimativas, elaboradas pelo ITA, de utilização da capacidade dos sistemas de pista e de pátio dos aeroportos. Publicadas em McKinsey \& Company (2010), as estimativas são referentes a 2009 para o aeroporto de Campinas e a 2008 para os demais aeroportos. Para obtenção da variável saturação, definem-se 4 variáveis dummy: uma indicando que o grau de utilização do sistema de pista do aeroporto de origem é superior a $80 \%$, outra indicando que o grau de utilização do sistema de pátio do aeroporto de origem é superior a $80 \%$, outra indicando que o grau de utilização do sistema de pista do aeroporto de destino é superior a $80 \%$ e outra indicando que o grau de utilização do sistema de pátio do aeroporto de destino é superior a $80 \%$. Saturação é a soma dessas quatro variáveis dummy e situa-se entre 0 e 4. Não havendo estimativas para o aeroporto de Campo Grande, considerou-se que o grau de utilização dos sistemas de pista e de pátio desse aeroporto era não maior que $80 \%$.

Renda média rota: Variável construída a partir da variável renda e definida como a média de renda entre os entrevistados na rota.

Trabalho proporção rota: Variável construída a partir da variável trabalho e definida como a proporção de entrevistados na rota para os quais trabalho é igual a 1.

\subsection{2.}

\section{Preenchimento de dados não informados}

Nos casos em que os entrevistados na Pesquisa O/D reportaram o número do voo, mas não informaram o aeroporto de destino ou a companhia aérea ou o horário de partida do voo, esses dados foram extraídos do Hotran (Horário de Transporte). Trata-se de uma listagem de todos os voos feita pela Anac, em que constam informações básicas de cada voo. 
A data da entrevista foi útil para inferir a data estabelecida para a partida do voo, nos casos em que ela não foi informada. Dependendo do horário em que a entrevista foi realizada e do horário estabelecido para a partida do voo, considerou-se que o dia em que está prevista a partida do voo é o dia da entrevista ou o dia seguinte ou ainda o dia anterior.

\section{2.}

Desenvolvimentos algébricos

\subsection{1.}

\section{Relação entre $\beta$ e $\delta$}

Define-se $\varepsilon \equiv W T P-x \beta$. Se $E(W T P \mid x)=x \beta$, então $E(\varepsilon \mid x)=0$. Logo, $E\left(x^{\prime} \varepsilon\right)=E\left(x^{1^{\prime}} \varepsilon\right)=E\left({z^{2}}^{\prime} \varepsilon\right)=0$. A hipótese, contida em (2), de que $E\left(W T P \mid x ; z^{1}\right)=E(W T P \mid x)$ implica que $E\left(z^{1^{\prime}} \varepsilon\right)=0$. Dado que $E\left(z^{1^{\prime}} \varepsilon\right)=$ $E\left(z^{2^{\prime}} \varepsilon\right)=0$, tem-se que $E\left(z^{\prime} \varepsilon\right)=0$. Como $E(W T P \mid z)=z \delta$, conclui-se que $E(\zeta \mid z)=0$, o que implica $E\left(z^{\prime} \zeta\right)=0$.

Pré-multiplicando a expressão $W T P=x \beta+\varepsilon$ por $z^{\prime}$ e tomando a esperança:

$E\left(z^{\prime} W T P\right)=E\left(z^{\prime} x\right) \beta+E\left(z^{\prime} \varepsilon\right)$

$E\left(z^{\prime}(z \delta+\zeta)\right)=E\left(z^{\prime} x\right) \beta$

$E\left(z^{\prime} z\right) \delta=E\left(z^{\prime} x\right) \beta$

\subsection{2.}

\section{Excedente do consumidor}

Seja $p$ tal que $\operatorname{Pr}(W T P \geq p \mid z) \neq 0$. Então:

$E(W T P-p \mid W T P \geq p ; z)=$

$=E(z \delta+\zeta-p \mid \zeta \geq p-z \delta ; z)=z \delta-p+E(\zeta \mid \zeta \geq p-z \delta)$

A restrição de que $\operatorname{Pr}(W T P \geq p \mid z) \neq 0$ implica que $p-z \delta<a$. Há dois casos a considerar:

Caso 1: $-a \leq p-z \delta<a$

$E(\zeta \mid \zeta \geq p-z \delta)=\frac{2 a}{(a-p+z \delta)} \int_{p-z \delta}^{a} t \frac{1}{2 a} d t=\frac{a^{2}-(p-z \delta)^{2}}{2(a-p+z \delta)}=\frac{a+p-z \delta}{2}$

$E(W T P-p \mid W T P \geq p ; z)=z \delta-p+\frac{a+p-z \delta}{2}=\frac{a-p+z \delta}{2}$ 
Caso 2: $p-z \delta \leq-a$

$E(\zeta \mid \zeta \geq p-z \delta)=E(\zeta)=0$

$E(W T P-p \mid W T P \geq p ; z)=z \delta-p$

Logo, $E(W T P-p \mid W T P \geq p ; z)$ é dado por:

$\begin{cases}\frac{(a+z \delta-p)}{2} & \text { se } z \delta-p \leq a \\ z \delta-p & \text { se } z \delta-p \geq a\end{cases}$

8.3.

Figuras e tabelas

Figura 2 - Relação entre $\operatorname{Pr}\left(W T P \geq p \mid z^{R}\right)$ e $p$

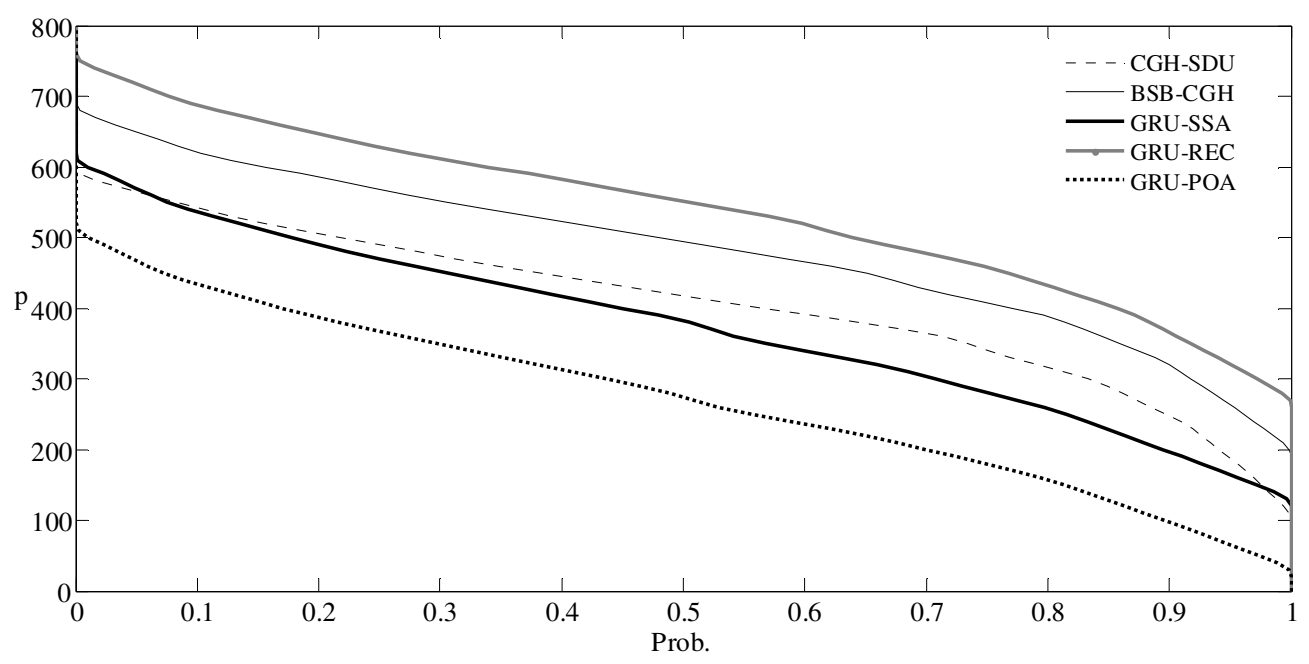

Notas: (1) Empregados os parâmetros estimados na especificação (1). (2) No eixo vertical, preços em $R$ \$. (3) No eixo horizontal, $\operatorname{Pr}\left(W T P \geq p \mid z^{R}\right)$. (4) Apresentados resultados para as 5 rotas com maior tráfego de passageiros em 2009. (5) A correspondência entre a localização dos aeroportos e os códigos IATA consta da lista de abreviaturas. 
Tabela 6 - Preços (em R\$) no modelo e nos contrafactuais, com base nos parâmetros estimados na especificação (1)

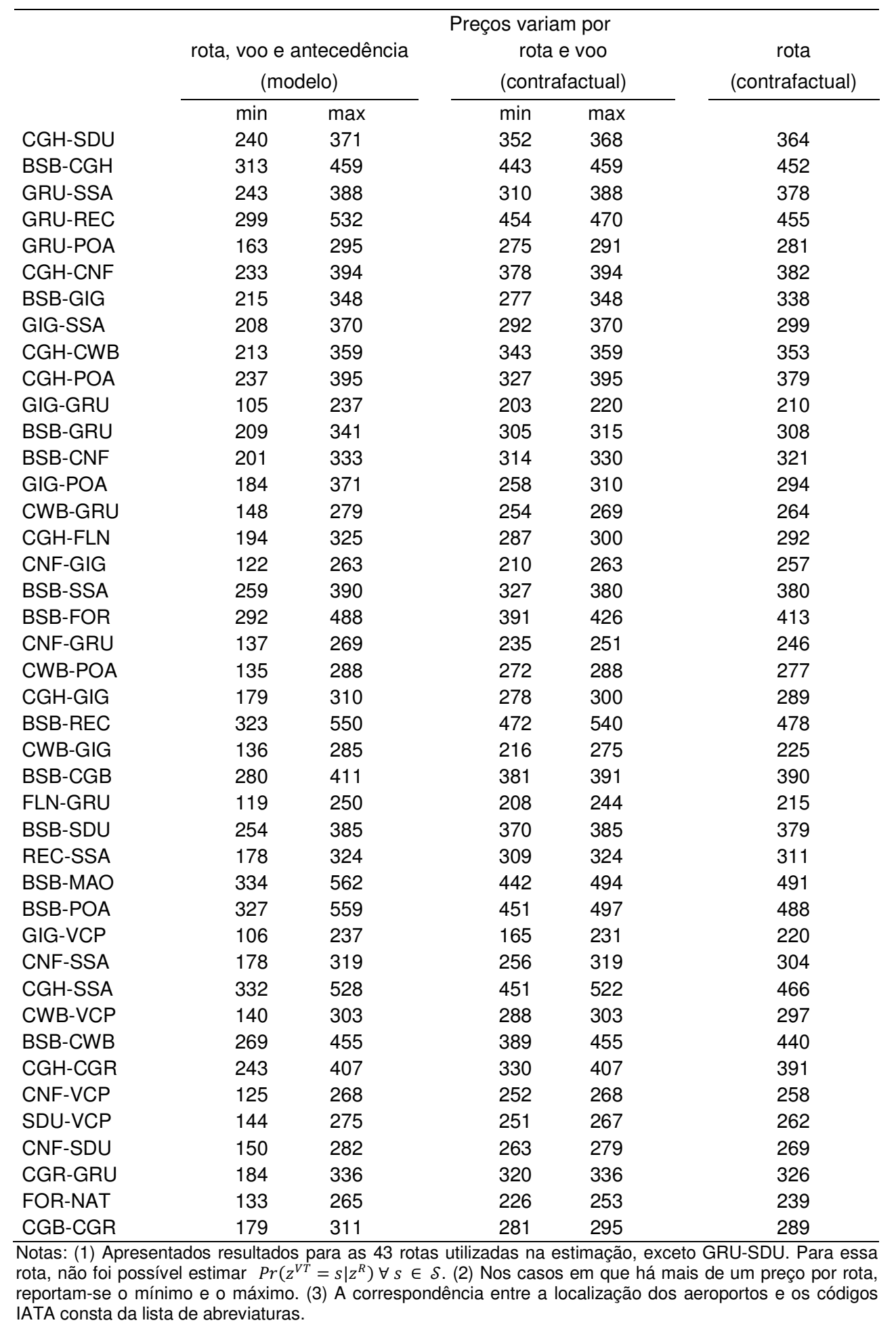


Tabela 7 - Preços (em R\$) no modelo e nos contrafactuais, com base nos parâmetros estimados na especificação (2)

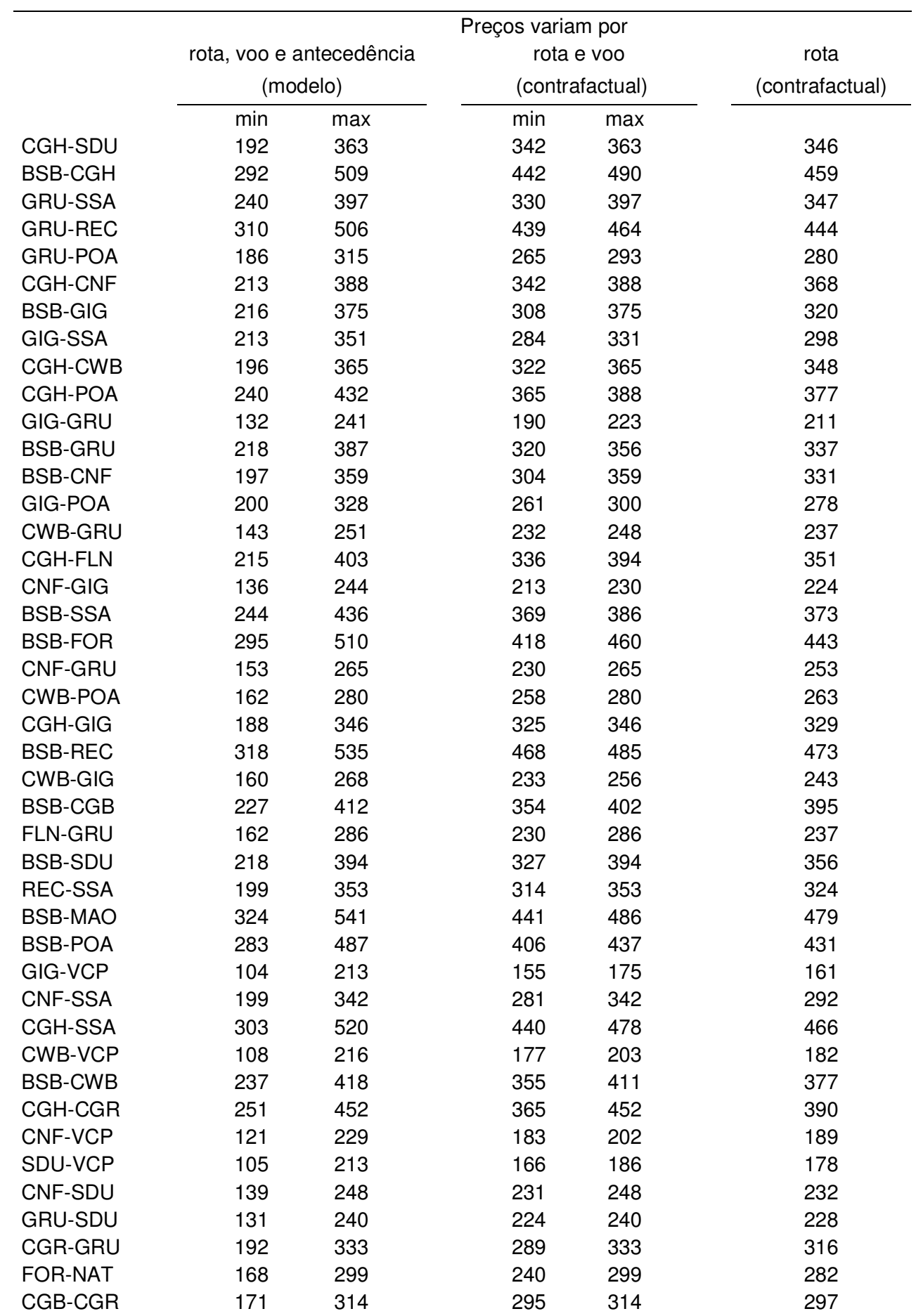

Notas: (1) Apresentados resultados para as 43 rotas utilizadas na estimação. (2) Nos casos em que há mais de um preço por rota, reportam-se o mínimo e o máximo. (3) A correspondência entre a localização dos aeroportos e os códigos IATA consta da lista de abreviaturas. 
Tabela 8 - Variação percentual das medidas de bem-estar entre cada contrafactual e o modelo, com base nos parâmetros estimados na especificação (1)

\begin{tabular}{|c|c|c|c|c|c|c|}
\hline & \multicolumn{6}{|c|}{ Contrafactual } \\
\hline & \multicolumn{3}{|c|}{ Preços variam por rota e voo } & \multicolumn{3}{|c|}{ Preços variam por rota } \\
\hline & $E\left(C S \mid z^{R}\right)$ & $E\left(\Pi \mid z^{R}\right)$ & $\begin{array}{c}E\left(C S \mid z^{R}\right) \\
+E\left(\Pi \mid z^{R}\right)\end{array}$ & $E\left(C S \mid z^{R}\right)$ & $E\left(\Pi \mid z^{R}\right)$ & $\begin{array}{r}E\left(C S \mid z^{R}\right) \\
+E\left(\Pi \mid z^{R}\right)\end{array}$ \\
\hline CGH-SDU & $-9 \%$ & $-5 \%$ & $-6 \%$ & $-13 \%$ & $-6 \%$ & $-8 \%$ \\
\hline BSB-CGH & $-25 \%$ & $-9 \%$ & $-14 \%$ & $-25 \%$ & $-10 \%$ & $-15 \%$ \\
\hline GRU-SSA & $-8 \%$ & $-15 \%$ & $-13 \%$ & $-31 \%$ & $-17 \%$ & $-22 \%$ \\
\hline GRU-REC & $-8 \%$ & $-17 \%$ & $-15 \%$ & $-3 \%$ & $-17 \%$ & $-14 \%$ \\
\hline GRU-POA & $-22 \%$ & $-14 \%$ & $-17 \%$ & $-22 \%$ & $-15 \%$ & $-17 \%$ \\
\hline $\mathrm{CGH}-\mathrm{CNF}$ & $-28 \%$ & $-10 \%$ & $-15 \%$ & $-26 \%$ & $-10 \%$ & $-15 \%$ \\
\hline BSB-GIG & $-4 \%$ & $-14 \%$ & $-11 \%$ & $-27 \%$ & $-16 \%$ & $-19 \%$ \\
\hline GIG-SSA & $-6 \%$ & $-15 \%$ & $-13 \%$ & $+1 \%$ & $-16 \%$ & $-11 \%$ \\
\hline $\mathrm{CGH}-\mathrm{CWB}$ & $-21 \%$ & $-7 \%$ & $-12 \%$ & $-23 \%$ & $-8 \%$ & $-12 \%$ \\
\hline CGH-POA & $-24 \%$ & $-13 \%$ & $-17 \%$ & $-29 \%$ & $-14 \%$ & $-19 \%$ \\
\hline GIG-GRU & $-1 \%$ & $-12 \%$ & $-9 \%$ & $0 \%$ & $-13 \%$ & $-8 \%$ \\
\hline BSB-GRU & $+2 \%$ & $-11 \%$ & $-7 \%$ & $+2 \%$ & $-11 \%$ & $-7 \%$ \\
\hline BSB-CNF & $-17 \%$ & $-11 \%$ & $-13 \%$ & $-18 \%$ & $-11 \%$ & $-13 \%$ \\
\hline GIG-POA & $-3 \%$ & $-18 \%$ & $-14 \%$ & $-4 \%$ & $-19 \%$ & $-15 \%$ \\
\hline CWB-GRU & $-10 \%$ & $-9 \%$ & $-9 \%$ & $-12 \%$ & $-9 \%$ & $-10 \%$ \\
\hline CGH-FLN & $+5 \%$ & $-8 \%$ & $-4 \%$ & $+6 \%$ & $-8 \%$ & $-4 \%$ \\
\hline CNF-GIG & $-14 \%$ & $-10 \%$ & $-12 \%$ & $-26 \%$ & $-11 \%$ & $-16 \%$ \\
\hline BSB-SSA & $-12 \%$ & $-13 \%$ & $-13 \%$ & $-24 \%$ & $-14 \%$ & $-17 \%$ \\
\hline BSB-FOR & $-6 \%$ & $-17 \%$ & $-14 \%$ & $-7 \%$ & $-17 \%$ & $-14 \%$ \\
\hline CNF-GRU & $0 \%$ & $-8 \%$ & $-5 \%$ & $-3 \%$ & $-8 \%$ & $-6 \%$ \\
\hline CWB-POA & $-27 \%$ & $-10 \%$ & $-15 \%$ & $-26 \%$ & $-10 \%$ & $-15 \%$ \\
\hline CGH-GIG & $0 \%$ & $-6 \%$ & $-4 \%$ & $-2 \%$ & $-6 \%$ & $-5 \%$ \\
\hline BSB-REC & $-15 \%$ & $-14 \%$ & $-14 \%$ & $+1 \%$ & $-14 \%$ & $-11 \%$ \\
\hline CWB-GIG & $-1 \%$ & $-15 \%$ & $-11 \%$ & $+5 \%$ & $-16 \%$ & $-10 \%$ \\
\hline BSB-CGB & $0 \%$ & $-5 \%$ & $-4 \%$ & $-2 \%$ & $-5 \%$ & $-4 \%$ \\
\hline FLN-GRU & $+9 \%$ & $-9 \%$ & $-3 \%$ & $+11 \%$ & $-10 \%$ & $-3 \%$ \\
\hline BSB-SDU & $-20 \%$ & $-10 \%$ & $-13 \%$ & $-22 \%$ & $-11 \%$ & $-14 \%$ \\
\hline REC-SSA & $-28 \%$ & $-10 \%$ & $-16 \%$ & $-25 \%$ & $-10 \%$ & $-15 \%$ \\
\hline BSB-MAO & $+1 \%$ & $-16 \%$ & $-12 \%$ & $-2 \%$ & $-16 \%$ & $-13 \%$ \\
\hline BSB-POA & $-1 \%$ & $-16 \%$ & $-12 \%$ & $-6 \%$ & $-16 \%$ & $-14 \%$ \\
\hline GIG-VCP & $-9 \%$ & $-12 \%$ & $-11 \%$ & $-19 \%$ & $-14 \%$ & $-16 \%$ \\
\hline CNF-SSA & $-8 \%$ & $-14 \%$ & $-12 \%$ & $-29 \%$ & $-15 \%$ & $-20 \%$ \\
\hline CGH-SSA & $-11 \%$ & $-15 \%$ & $-14 \%$ & $-5 \%$ & $-16 \%$ & $-13 \%$ \\
\hline CWB-VCP & $-30 \%$ & $-13 \%$ & $-18 \%$ & $-29 \%$ & $-13 \%$ & $-18 \%$ \\
\hline BSB-CWB & $-15 \%$ & $-12 \%$ & $-13 \%$ & $-29 \%$ & $-13 \%$ & $-18 \%$ \\
\hline CGH-CGR & $-8 \%$ & $-11 \%$ & $-10 \%$ & $-31 \%$ & $-14 \%$ & $-19 \%$ \\
\hline CNF-VCP & $-27 \%$ & $-12 \%$ & $-17 \%$ & $-27 \%$ & $-13 \%$ & $-18 \%$ \\
\hline SDU-VCP & $-10 \%$ & $-9 \%$ & $-10 \%$ & $-13 \%$ & $-10 \%$ & $-11 \%$ \\
\hline CNF-SDU & $-12 \%$ & $-7 \%$ & $-9 \%$ & $-13 \%$ & $-8 \%$ & $-10 \%$ \\
\hline CGR-GRU & $-26 \%$ & $-12 \%$ & $-16 \%$ & $-27 \%$ & $-13 \%$ & $-17 \%$ \\
\hline FOR-NAT & $-1 \%$ & $-10 \%$ & $-7 \%$ & $-6 \%$ & $-10 \%$ & $-9 \%$ \\
\hline CGB-CGR & $+1 \%$ & $-4 \%$ & $-2 \%$ & $-3 \%$ & $-4 \%$ & $-4 \%$ \\
\hline
\end{tabular}


Tabela 9 - Variação percentual das medidas de bem-estar entre cada contrafactual e o modelo, com base nos parâmetros estimados na especificação (2)

\begin{tabular}{|c|c|c|c|c|c|c|}
\hline & \multicolumn{6}{|c|}{ Contrafactual } \\
\hline & \multicolumn{3}{|c|}{ Preços variam por rota e voo } & \multicolumn{3}{|c|}{ Preços variam por rota } \\
\hline & $E\left(C S \mid z^{R}\right)$ & $E\left(\Pi \mid z^{R}\right)$ & $\begin{array}{r}E\left(C S \mid z^{R}\right) \\
+E\left(\Pi \mid z^{R}\right)\end{array}$ & $E\left(C S \mid z^{R}\right)$ & $E\left(\Pi \mid z^{R}\right)$ & $\begin{array}{r}E\left(C S \mid z^{R}\right) \\
+E\left(\Pi \mid z^{R}\right)\end{array}$ \\
\hline CGH-SDU & $-21 \%$ & $-7 \%$ & $-11 \%$ & $-16 \%$ & $-8 \%$ & $-10 \%$ \\
\hline BSB-CGH & $-6 \%$ & $-10 \%$ & $-9 \%$ & $-1 \%$ & $-11 \%$ & $-9 \%$ \\
\hline GRU-SSA & $-13 \%$ & $-12 \%$ & $-12 \%$ & $-9 \%$ & $-13 \%$ & $-12 \%$ \\
\hline GRU-REC & $-12 \%$ & $-13 \%$ & $-13 \%$ & $-8 \%$ & $-13 \%$ & $-12 \%$ \\
\hline GRU-POA & $-14 \%$ & $-11 \%$ & $-12 \%$ & $-13 \%$ & $-11 \%$ & $-12 \%$ \\
\hline $\mathrm{CGH}-\mathrm{CNF}$ & $-18 \%$ & $-9 \%$ & $-11 \%$ & $-22 \%$ & $-10 \%$ & $-13 \%$ \\
\hline BSB-GIG & $-14 \%$ & $-11 \%$ & $-12 \%$ & $-9 \%$ & $-13 \%$ & $-11 \%$ \\
\hline GIG-SSA & $-9 \%$ & $-11 \%$ & $-10 \%$ & $-8 \%$ & $-11 \%$ & $-11 \%$ \\
\hline $\mathrm{CGH}-\mathrm{CWB}$ & $-21 \%$ & $-8 \%$ & $-11 \%$ & $-20 \%$ & $-8 \%$ & $-11 \%$ \\
\hline CGH-POA & $-5 \%$ & $-12 \%$ & $-10 \%$ & $-6 \%$ & $-12 \%$ & $-10 \%$ \\
\hline GIG-GRU & $-1 \%$ & $-10 \%$ & $-7 \%$ & $-3 \%$ & $-11 \%$ & $-8 \%$ \\
\hline BSB-GRU & $-7 \%$ & $-12 \%$ & $-11 \%$ & $-10 \%$ & $-13 \%$ & $-12 \%$ \\
\hline BSB-CNF & $-18 \%$ & $-11 \%$ & $-13 \%$ & $-20 \%$ & $-11 \%$ & $-14 \%$ \\
\hline GIG-POA & $-9 \%$ & $-12 \%$ & $-11 \%$ & $-7 \%$ & $-13 \%$ & $-11 \%$ \\
\hline CWB-GRU & $-14 \%$ & $-6 \%$ & $-9 \%$ & $-11 \%$ & $-7 \%$ & $-8 \%$ \\
\hline CGH-FLN & $-8 \%$ & $-11 \%$ & $-10 \%$ & $-7 \%$ & $-12 \%$ & $-10 \%$ \\
\hline CNF-GIG & $-4 \%$ & $-6 \%$ & $-5 \%$ & $-7 \%$ & $-7 \%$ & $-7 \%$ \\
\hline BSB-SSA & $-7 \%$ & $-12 \%$ & $-11 \%$ & $-5 \%$ & $-12 \%$ & $-10 \%$ \\
\hline BSB-FOR & $-12 \%$ & $-13 \%$ & $-13 \%$ & $-12 \%$ & $-14 \%$ & $-13 \%$ \\
\hline CNF-GRU & $-16 \%$ & $-6 \%$ & $-9 \%$ & $-15 \%$ & $-8 \%$ & $-10 \%$ \\
\hline CWB-POA & $-19 \%$ & $-6 \%$ & $-10 \%$ & $-16 \%$ & $-7 \%$ & $-10 \%$ \\
\hline CGH-GIG & $-23 \%$ & $-8 \%$ & $-12 \%$ & $-20 \%$ & $-8 \%$ & $-12 \%$ \\
\hline BSB-REC & $-6 \%$ & $-11 \%$ & $-10 \%$ & $-3 \%$ & $-11 \%$ & $-9 \%$ \\
\hline CWB-GIG & $-10 \%$ & $-10 \%$ & $-10 \%$ & $-11 \%$ & $-10 \%$ & $-10 \%$ \\
\hline BSB-CGB & $-15 \%$ & $-8 \%$ & $-10 \%$ & $-21 \%$ & $-9 \%$ & $-12 \%$ \\
\hline FLN-GRU & $-7 \%$ & $-11 \%$ & $-10 \%$ & $-6 \%$ & $-11 \%$ & $-10 \%$ \\
\hline BSB-SDU & $-11 \%$ & $-10 \%$ & $-10 \%$ & $-13 \%$ & $-11 \%$ & $-12 \%$ \\
\hline REC-SSA & $-17 \%$ & $-9 \%$ & $-11 \%$ & $-19 \%$ & $-10 \%$ & $-12 \%$ \\
\hline BSB-MAO & $-4 \%$ & $-13 \%$ & $-11 \%$ & $-6 \%$ & $-13 \%$ & $-11 \%$ \\
\hline BSB-POA & $-8 \%$ & $-12 \%$ & $-11 \%$ & $-11 \%$ & $-13 \%$ & $-12 \%$ \\
\hline GIG-VCP & $+25 \%$ & $-10 \%$ & $+2 \%$ & $+25 \%$ & $-10 \%$ & $+2 \%$ \\
\hline CNF-SSA & $-11 \%$ & $-11 \%$ & $-11 \%$ & $-10 \%$ & $-11 \%$ & $-11 \%$ \\
\hline CGH-SSA & $-6 \%$ & $-12 \%$ & $-11 \%$ & $-9 \%$ & $-13 \%$ & $-12 \%$ \\
\hline CWB-VCP & $+11 \%$ & $-6 \%$ & $-1 \%$ & $+12 \%$ & $-7 \%$ & $-1 \%$ \\
\hline BSB-CWB & $-13 \%$ & $-10 \%$ & $-11 \%$ & $-9 \%$ & $-10 \%$ & $-10 \%$ \\
\hline CGH-CGR & $-15 \%$ & $-10 \%$ & $-11 \%$ & $-2 \%$ & $-12 \%$ & $-9 \%$ \\
\hline CNF-VCP & $+13 \%$ & $-7 \%$ & $-1 \%$ & $+12 \%$ & $-8 \%$ & $-1 \%$ \\
\hline SDU-VCP & $+12 \%$ & $-6 \%$ & $0 \%$ & $+11 \%$ & $-7 \%$ & $-1 \%$ \\
\hline CNF-SDU & $-13 \%$ & $-5 \%$ & $-8 \%$ & $-10 \%$ & $-6 \%$ & $-7 \%$ \\
\hline GRU-SDU & $-10 \%$ & $-5 \%$ & $-7 \%$ & $-10 \%$ & $-6 \%$ & $-7 \%$ \\
\hline CGR-GRU & $-18 \%$ & $-9 \%$ & $-12 \%$ & $-24 \%$ & $-10 \%$ & $-14 \%$ \\
\hline FOR-NAT & $-16 \%$ & $-9 \%$ & $-11 \%$ & $-25 \%$ & $-10 \%$ & $-15 \%$ \\
\hline CGB-CGR & $-22 \%$ & $-5 \%$ & $-10 \%$ & $-19 \%$ & $-6 \%$ & $-10 \%$ \\
\hline
\end{tabular}

